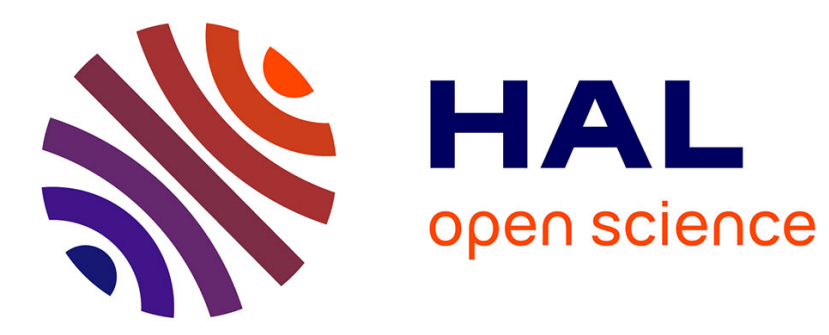

\title{
Numerical simulation of an oxygen-fed wire-to-cylinder negative corona discharge in the glow regime
}

\author{
K Yanallah, F Pontiga, A Castellanos
}

\section{To cite this version:}

K Yanallah, F Pontiga, A Castellanos. Numerical simulation of an oxygen-fed wire-to-cylinder negative corona discharge in the glow regime. Journal of Physics D: Applied Physics, 2011, 44 (5), pp.55201. 10.1088/0022-3727/44/5/055201 . hal-00591292

\section{HAL Id: hal-00591292 \\ https://hal.science/hal-00591292}

Submitted on 9 May 2011

HAL is a multi-disciplinary open access archive for the deposit and dissemination of scientific research documents, whether they are published or not. The documents may come from teaching and research institutions in France or abroad, or from public or private research centers.
L'archive ouverte pluridisciplinaire HAL, est destinée au dépôt et à la diffusion de documents scientifiques de niveau recherche, publiés ou non, émanant des établissements d'enseignement et de recherche français ou étrangers, des laboratoires publics ou privés. 


\title{
Numerical simulation of an oxygen-fed wire-to-cylinder negative corona discharge in the glow regime
}

\author{
K. Yanallah ${ }^{1,2}$, F. Pontiga ${ }^{1}$, and A. Castellanos ${ }^{2}$ \\ ${ }^{1}$ Dpt. Física Aplicada II, Universidad de Sevilla, Spain. \\ ${ }^{2}$ Dpt. Electrónica y Electromagnetismo, Universidad de Sevilla, Spain.
}

\begin{abstract}
Negative glow corona discharge in flowing oxygen has been numerically simulated for a wire-to-cylinder electrode geometry. The corona discharge is modelled using a fluid approximation. The radial and axial distributions of charged and neutral species are obtained by solving the corresponding continuity equations, which include the relevant plasma-chemical kinetics. Continuity equations are coupled with Poisson's equation and the energy conservation equation, since the reaction rate constants may depend on the electric field and temperature. The experimental values of the current-voltage characteristic are used as input data into the numerical calculations. The role played by different reactions and chemical species is analyzed, and the effect of electrical and geometrical parameters on ozone generation is investigated. The reliability of the numerical model is verified by the reasonable agreement between the numerical predictions of ozone concentration and the experimental measurements.
\end{abstract}

Keywords: Corona discharge; Fluid model; Chemical reactions; Ozone production; Gas flow.

\section{Introduction}

The numerical simulation of electrical discharges in gases is certainly a difficult task, since equations of very diverse nature (Gauss equation, conservation and transport equations, energy equation, etc.) must be simultaneously solved. Moreover, these equations are strongly coupled through the chemical kinetics of species and the dependence of the reaction rate constants with the electric field and temperature. Therefore, different simplifications are usually introduced in order to reduce the complexity of the problem. For example, wire-cylinder streamer corona discharge has been simulated by Hadj-Ziane et al [1,2] and Loiseau et al [3] assuming that electronic injections, with azimuthal symmetry, occurred at certain sites along the corona wire. The injected electron density was given as an empirical law, and the dependence of reaction rate constants with the electric field was not taken into account. Chen and Davidson [4,5] have used a corona plasma model to determine the electron and ion densities. The ionization region was assumed to be symmetrical about the corona wire. Then, the rate of electron impact reactions was computed and introduced into chemistry model to determine the concentration of neutral species within the air stream of a corona wire-plate electrode system. A similar approach has recently been used by Wang and Chen [6] to investigate ozone generation in air using wirecylinder corona discharge.

In the past, the authors have also investigated the generation of ozone in wire-cylinder geometry using negative [7,8] and positive [9] corona. The electrical discharge was modeled as stationary and symmetrical around the corona wire, as done by other investigators [4,5,6]. However, in these previous studies, the corona discharge reactor was assumed to operate in flow-stopped 

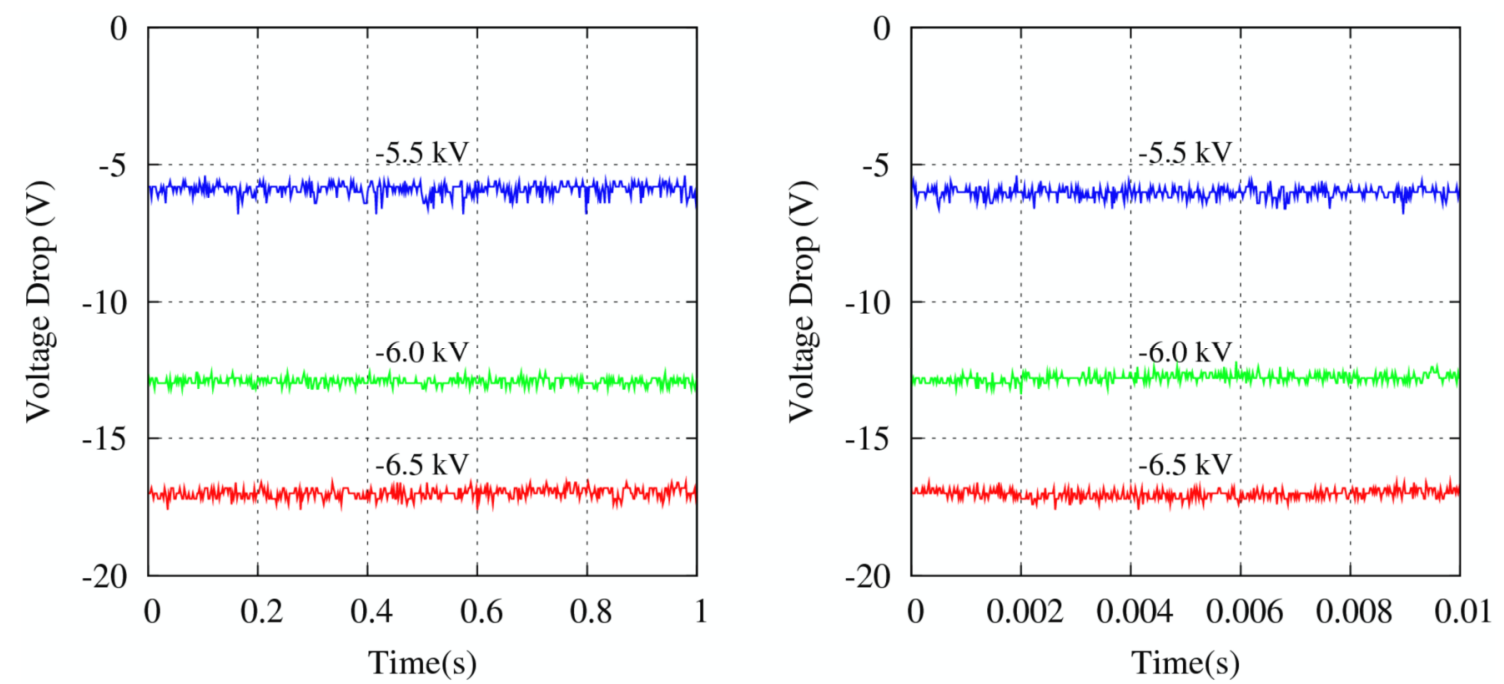

Figure 1: Voltage drop between the anode (cylinder) and the ground across a $0.1 \mathrm{M} \Omega$ resistance, for different values of the HV applied to the corona wire $\left(R=0.85 \mathrm{~cm}, Q=200 \mathrm{~cm}^{3} / \mathrm{min}\right)$.

conditions, that is, no gas flow was imposed along the cylinder. Therefore, the numerical model was one-dimensional, and the electric field and species distribution were determined as a function of the radial distance. In contrast, in the present work, an axial gas flow is assumed to exist through the cylinder, and a two-dimensional numerical model is used in order to determine the axial and radial distribution of charged and neutral species. Thus, the corona reactor will operate as an ozonizer, where pure oxygen enters the cylinder and ozone and other by-products are collected at the exit. Contrary to other studies [1-6], the governing equations will be simultaneously solved for all species, thus providing a revealing picture of the interplay between electrons, neutral species and the different types of ions. The effects of ozone decomposition on the electrode surface and Joule heating due to the electrical current will also be included in the numerical model. Finally, special attention will be paid to the influence of electrical and geometrical parameters on ozone generation.

To summarize, the following simplifications has been assumed in the numerical simulation: (1) the corona discharge is stationary (time-independent), (2) the corona discharge has azimuthal symmetry around the corona wire (no angular dependence), (3) the gas velocity is axially directed and it is solely determined by the gas flow rate, and (4) Joule heating dissipation is the dominant source of heat generation inside the corona discharge reactor. The consequences and validity of these simplifications will be thoroughly discussed in the paper.

\section{Experimental set-up}

The experimental set-up is similar to the one used in previous works $[8,9]$. The corona discharge reactor consists of a smooth tungsten wire, with radius $r_{0}=0.05 \mathrm{~mm}$, placed along the axis of a stainless steel cylinder. Three different cylinder radii were used in the experiments, $R=6.5,8.5$ and $11 \mathrm{~mm}$. Both the wire and the cylinder have a total length $L=5 \mathrm{~cm}$. The two ends of the cylinder are closed with ultraviolet-grade fused silica parallel windows, so as to allow ultraviolet spectroscopic measurements. High purity oxygen $(99.995 \%)$ was continuously injected into the cylinder at room temperature and at atmospheric pressure. The oxygen flow rate, $Q$, was controlled with the help of a mass flow controller (Omega FMA-2618A) in the range $100-200 \mathrm{cc} / \mathrm{min}$, which is appropriate for practical ozonizers based on corona discharge [10].

The entire discharge cell was placed inside the sample compartment of a ultraviolet-visible spectrophotometer (Nicolet Evolution 300) that monitors periodically the absorbance of the gas between 190 and $320 \mathrm{~nm}$. Within this wavelength range, the absorption cross section of ozone exhibits a broad peak, with a maximum value of $1159 \times 10^{-20} \mathrm{~cm}^{2} /$ molecule at $254 \mathrm{~nm}$. The 

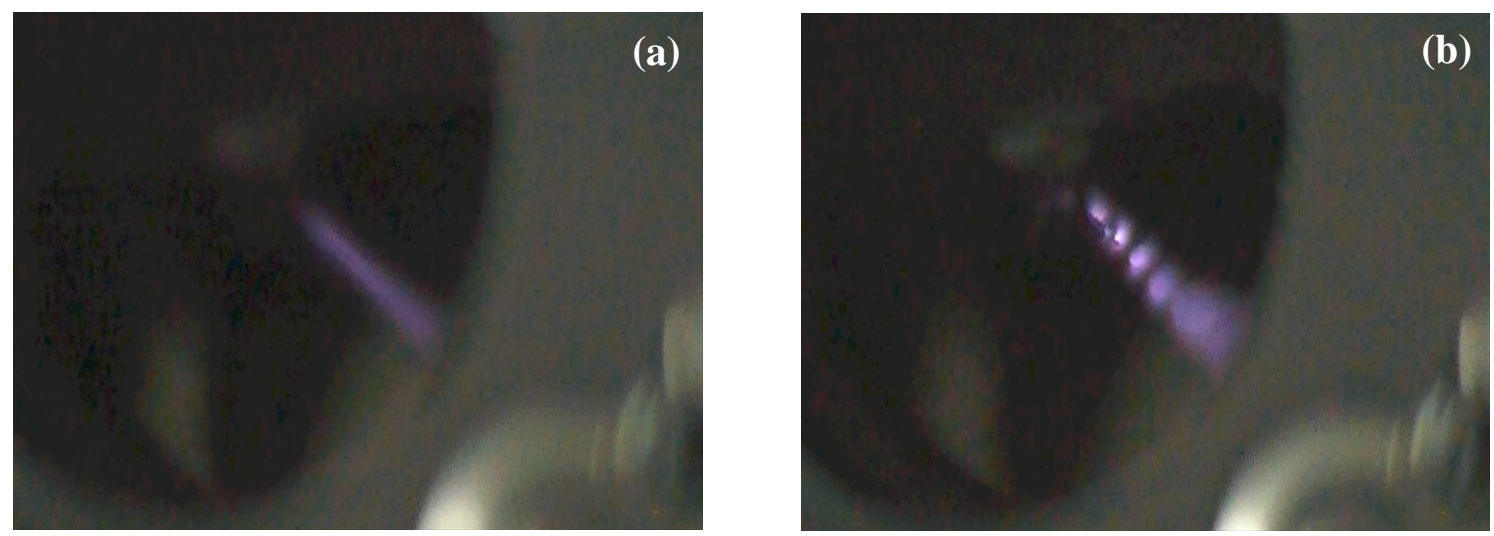

Figure 2. Light emission from the ionization region surrounding the corona wire for an applied voltage of $-6 \mathrm{kV}$ (a) and $-8 \mathrm{kV}(\mathrm{b})$. The gas flow rate was set at $157.5 \mathrm{~cm}^{3} / \mathrm{min}\left(95.2 \% \mathrm{O}_{2}, 4.8 \% \mathrm{~N}_{2}\right)$.

ultraviolet beam emitted by the specrophotometer has a rectangular cross sectional area of about $0.5 \mathrm{~cm} \times 1 \mathrm{~cm}$, and travels parallel to the axis of the cylinder. Therefore, spectrophotometric measurements give the averaged absorption in the entire volume of the gas discharge reactor. Ozone concentration was determined by applying the well known Beer-Lambert law [11]. Least square fitting was used to obtain a more precise quantification.

Negative DC high voltage was applied to the wire using a Trek-610C amplifier, and the timeaveraged electrical current was measured using a digital multimeter (Keithley 196). The oscillogram in figure 1 shows the voltage drop across a resistance of $0.1 \mathrm{M} \Omega$ bridging the anode and the ground. In the range of applied voltages, the current intensity can be approximated as stationary. As indicated by Vann Bush and Snyder [12] and by Chang et al [13], the use of thin and smooth electrodes favours the generation of a glow corona (or "ideal corona" as term by Vann Bush and Snyder). This condition was fulfilled in our experimental, and the existence of a stable glow corona was confirmed in the range -4.5 to $-6.5 \mathrm{kV}$ by observing the homogeneity of the light emitted from the ionization region surrounding the corona discharge. In these observations, oxygen was doped with a small amount of nitrogen $(\sim 5 \%)$ in order to increase the emission of light in the visible spectrum. At higher applied voltages (above $-7 \mathrm{kV}$ ) transition to the tuft corona regime was observed. Figures $2 \mathrm{a}$ and $2 \mathrm{~b}$ show two photographs of the corona wire with a macro lens $(\times 2)$ when the applied voltage was set at $-6 \mathrm{kV}$ (glow corona) and $-8 \mathrm{kV}$ (tuft corona), respectively.

The current-voltage characteristics obtained during the experiments for different gas flow rates is shown in Figure 3. The gas flow has a weak influence on the electrical current, but it affects the residence time of the gas within the discharge reactor and, therefore, the species concentration at the exit of the cylinder. The experimental values of the applied voltage and time-averaged current will be used as input data into the numerical simulation of the corona discharge.

\section{Problem formulation}

\subsection{General equations and approximations.}

Atmospheric pressure corona discharges can be successfully modelled using a fluid approximation, since the mean free path of particles is much smaller than the spatial scales associated to the electrical discharge. The fluid approximation consists in solving a continuity equation for every species participating in the electrical discharge,

$$
\frac{\partial N_{i}}{\partial t}+\nabla \cdot \mathbf{J}_{i}=S_{i}
$$




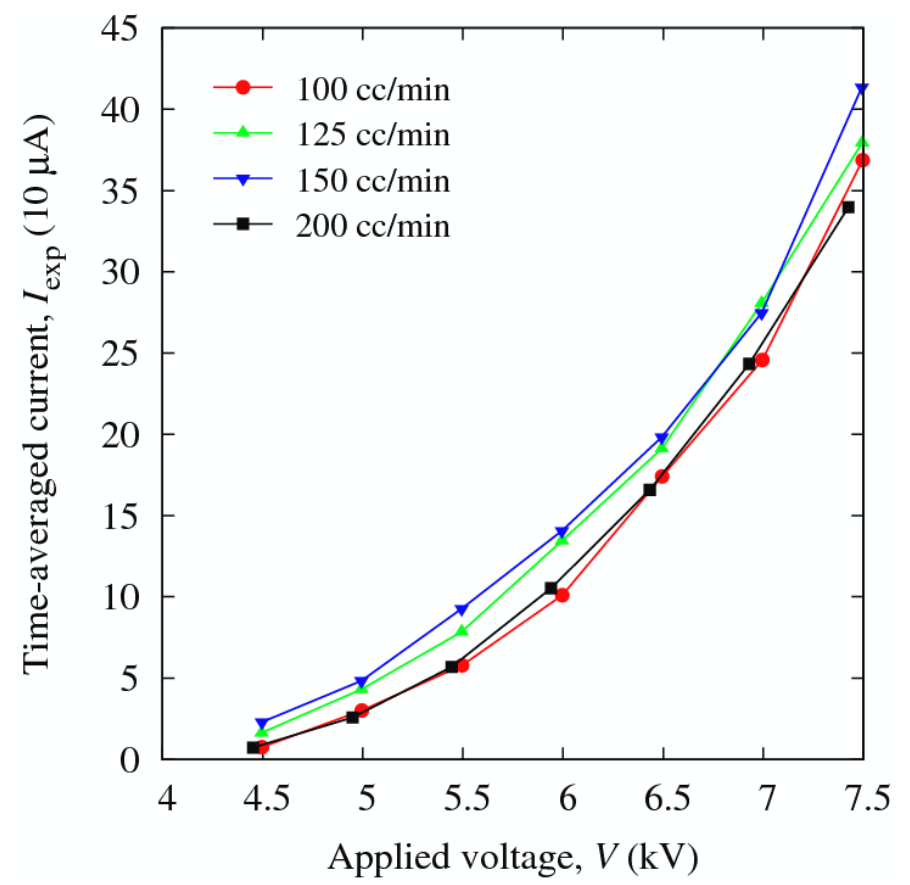

Figure 3. Time-averaged corona current as a function of applied voltage for different gas flow rates and a cylinder radius of $8.5 \mathrm{~mm}$.

where $N_{i}$ and $\mathbf{J}_{i}$ stand for the density and the flux of the $i$ th species, and $S_{i}$ represents its net production rate, which is determined by different gain and loss terms, as given by the reactions in Table 1. The transport of species can have several contributions: the velocity of the gas, molecular diffusion and, for charged species, drift under the applied electric field:

$$
\mathbf{J}_{i}=N_{i} \mathbf{v}-D_{i} \nabla N_{i}+\frac{e_{i}}{\left|e_{i}\right|} \mu_{i} N_{i} \mathbf{E},
$$

where $\mathbf{v}$ represents the gas velocity, $\mathbf{E}$ is the electric field, and $e_{i}, \mu_{i}$ and $D_{i}$ stand for the electrical charge, mobility and diffusion coefficient of the $i$ th species, respectively.

For a stationary flow, the conservation of mass states that the averaged velocity in the $z$ direction is related to the gas flow rate as $\bar{v}_{z}=Q / A$, where $A=\pi\left(R^{2}-r_{0}^{2}\right)$. In this work, the gas velocity is assumed to be constant and entirely determined by the gas flow rate, that is, $\mathbf{v}=\bar{v}_{z} \hat{\mathbf{z}}$. Coulomb force acting on the spatial charge density could induce the electrical motion of the gas in the radial direction (ionic wind). However, the electrohydrodynamic theory shows that it is the rotational character of the electric body force which determines the production of electrical vorticity and, therefore, the generation of secondary flows and turbulence [14]. Consequently, the electrode geometry becomes a critical factor in controlling the existence of electrically induced flows. In concentric cylindrical electrodes, concentric spheres and parallel plates, the body force is theoretically irrotational. Therefore, in these geometries it is possible to avoid electrical flow provided that the corona discharge is uniform. Moreover, the stability of the static solution can be estimated from the work of Agrait and Castellanos [15], who investigated the linear stability of a fluid confined between concentric cylinders and subjected to unipolar injection of charge from the inner cylinder. The corona discharge can be seen as an injector of negative ions emanating from the boundary of the active region $(\sim 0.5 \mathrm{~mm})$. In the range of voltages and currents here considered, the linear stability criterion is fulfilled.

Usually, the terms on the right-had-side of (2) have very dissimilar values. For example, for charged species only the last term need to be retained, since ion drift velocity $\left(\sim 10^{2} \mathrm{~cm} / \mathrm{s}\right)$ is considerably higher than the gas flow velocity $(\sim 1.5 \mathrm{~cm} / \mathrm{s})$ or molecular diffusion $\left(D / R \sim 10^{-4}\right.$ $\mathrm{cm} / \mathrm{s})$. 
Regarding the flux of neutral species, the chemical kinetics introduces another significant temporal scale: the mean lifetime of each type of particle. Excluding ozone, the mean lifetimes of neutral particles are very short. For example, the lifetime of oxygen atoms is $\tau_{k} \sim 2 \times 10^{-4} \mathrm{~s}$, and those of excited atoms are even shorter (see section 4.2). In contrast, the characteristic diffusion time $\left(\tau_{D} \sim R^{2} / D \sim 3 \mathrm{~s}\right)$ or the residence time $\left(\tau_{z} \sim L / v_{z} \sim 3-7 \mathrm{~s}\right)$ are much longer. Therefore, in a first approximation, the flux of neutral species could be neglected. However, the generation of neutral species occurs in the vicinity of the wire through electronic reactions, which give rise to strong density gradients in the radial direction. For example, oxygen atoms are distributed within a region of about $\Delta r \sim 0.04 \mathrm{~cm}$, with its maximum density located at $r \sim$ $0.025 \mathrm{~cm}$ from the axis. In such a small region, the action of molecular diffusion is very fast $\left(\tau_{D}\right.$ $\left.\sim(\Delta r / 2)^{2} / D \sim 10^{-3} \mathrm{~s}\right)$. Therefore, radial diffusion will be retained in (2) in order to get more accurate results.

Since the lifetime of ozone is much longer $(\sim 1 s)$, it is more prone to be affected by the different transport processes. However, like the rest of neutral species, ozone is also generated in the vicinity of the wire and, therefore, molecular diffusion is expected to play an important role in its extractions towards the drift region, particularly at the entrance of the cylinder where the radial density gradient must be important. In the axial direction, diffusion time $\left(\tau_{D} \sim L^{2} / D \sim 10^{2}\right.$ s) is substantially longer than the residence time of gas inside the discharge cell $(\sim 3-7 \mathrm{~s})$, and the former can be neglected.

Besides equation (1), the energy conservation equation must be solved for the gas temperature,

$$
\frac{\partial}{\partial t}\left(\rho c_{\mathrm{v}} T\right)+\nabla \cdot\left(\rho c_{\mathrm{v}} T \mathbf{v}\right)=-p \nabla \cdot \mathbf{v}+\nabla \cdot(k \nabla T)-\mathbf{E} \cdot \mathbf{J}+\Phi
$$

where $\rho$ and $T$ stand for gas density and temperature, $c_{\mathrm{v}}$ is the specific gas heat capacity at constant volume, $p$ is the gas pressure, $\mathbf{E} \cdot \mathbf{J}$ is Joule heating dissipation due to the current density, and $\Phi$ represents other sources of heat generation. In order to make the problem computationally tractable, the following approximations will be made. Firstly, the gas flow will be treated as inviscid and incompressible $(\nabla \cdot \mathbf{v}=0)$. Regarding Joule heating, only the ion current contribution will be considered, since the thermal transfer between electrons and gas molecules is very poor. Joule heating will be mainly localized in the proximity of the wire, owing to the high current density and intense electric field existing in that region. Among other sources of heat generation, the heat released/absorbed in of chemical reactions could be of certain importance. However, this effect has been investigated by Chen and Davison [4], and they concluded that the chemical activity has a negligible effect on the gas temperature. Therefore, it will be ignored in the present study $(\Phi \approx 0)$. Finally, the gas velocity will be taken as $\mathbf{v}=\bar{v}_{z} \hat{\mathbf{z}}$.

To close the model, Gauss equation needs to be solved for the electric field, in order to obtain a self-consistent electric field distribution,

$$
\nabla \cdot \mathbf{E}=\frac{1}{\varepsilon} \sum_{i} e_{i} N_{i},
$$

where $\varepsilon$ is the gas permittivity, and the electric field can be obtained as the gradient of an electrical potential $\phi, \mathbf{E}=-\nabla \phi$.

In the present study, the electrical discharge will be assumed to be stationary in time $(\partial / \partial t=0)$ and to have azimuthal symmetry around the corona wire. These assumptions are particularly adequate in the glow corona regime, which occurred in our experiments up to applied voltages of about $6.5 \mathrm{kV}$. However, as indicated by Chen and Davidson [16], the existence of a "tuft corona" regime does not necessarily invalidated the applicability of the model, provided that the density of tuft spots is sufficiently high. In fact, numerical models in wire-to-cylinder geometry frequently assume that corona discharge is homogeneous along the wire. For example, this 


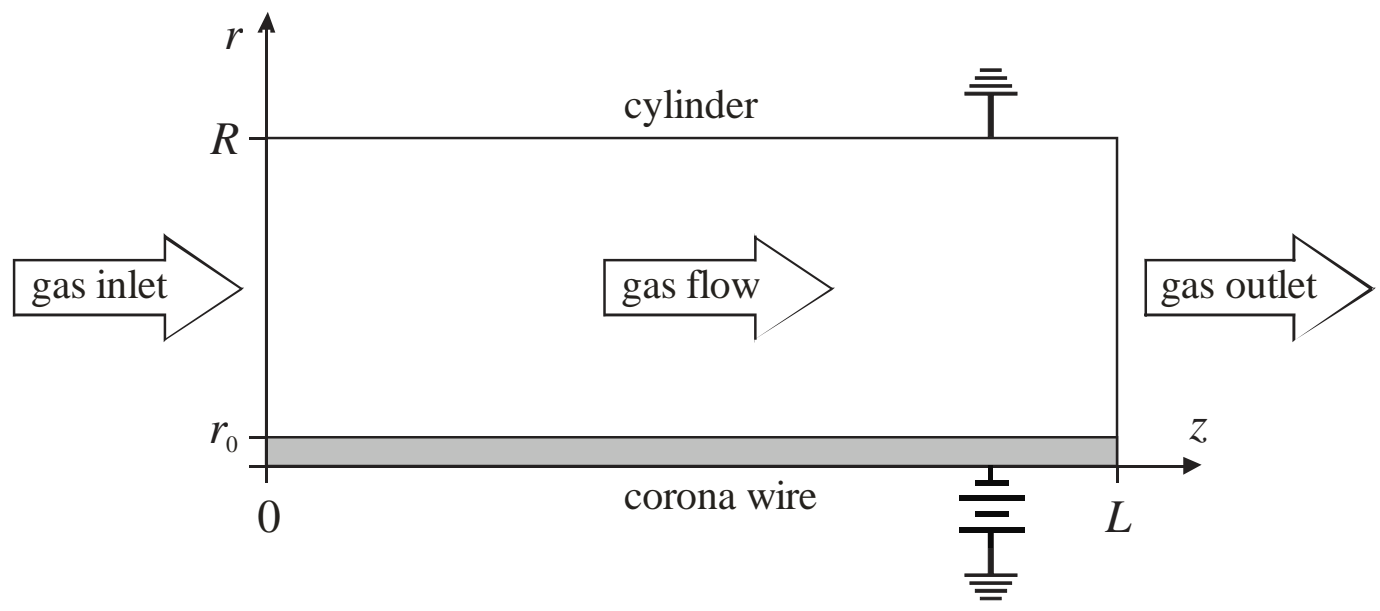

Figure 4. Integration domain in cylindrical coordinates.

approach is adopted in the works of Wang and Chen [6], Held and Peyrous [10], Mikoviny et al [17], Feng [18], Belevtsev and Biberman [19], etc.

Taking into account the above simplifications and using cylindrical coordinates $r$ and $z$ (2D problem), the spatial distribution of species, temperature and electric field will be governed by the following set of equations

$$
\begin{gathered}
\frac{1}{r} \frac{\partial}{\partial r}\left[r \frac{e_{i}}{\left|e_{i}\right|} \mu_{i} N_{i} E\right]=S_{i}, \\
v_{z} \frac{\partial N_{j}}{\partial z}-\frac{1}{r} \frac{\partial}{\partial r}\left[D_{j} \frac{\partial N_{j}}{\partial r}\right]=S_{j}, \\
v_{z} \frac{\partial}{\partial z}\left(\rho c_{\mathrm{v}} T\right)=\frac{1}{r} \frac{\partial}{\partial r}\left[r k \frac{\partial T}{\partial r}\right]-E J_{\text {ion }}, \\
\frac{1}{r} \frac{\partial}{\partial r}(r E)=\frac{1}{\varepsilon} \sum_{i} e_{i} N_{i}, \text { with } E=-\frac{\partial \phi}{\partial r},
\end{gathered}
$$

where $r_{0} \leq r \leq R, 0 \leq z \leq L$ (see figure 4), $i=\mathrm{e}, \mathrm{O}^{+}, \mathrm{O}_{2}{ }^{+}, \mathrm{O}_{3}{ }^{+}, \mathrm{O}^{-}, \mathrm{O}_{2}^{-}, \mathrm{O}_{3}^{-}$and $j=\mathrm{O}_{3} \mathrm{O}_{3}$, $\mathrm{O}\left({ }^{1} \mathrm{D}\right), \mathrm{O}_{2}\left({ }^{1} \Delta_{\mathrm{g}}\right), \mathrm{O}_{2}\left({ }^{1} \Sigma_{\mathrm{g}}{ }^{+}\right), \mathrm{O}_{2}{ }^{*}, \mathrm{O}_{3}{ }^{*}$. The last two chemical symbols, $\mathrm{O}_{2}{ }^{*}$ and $\mathrm{O}_{3}{ }^{*}$, represent vibrationally excited states of oxygen and ozone molecules, respectively. The number density of molecular oxygen is assumed to be constant, since only a very small fraction of $\mathrm{O}_{2}$ is decomposed by the electrical discharge. Electron mean energy and mobility have been obtained from the electron-swarm data compiled by Dutton [20].

\subsection{Boundary conditions}

Boundary conditions appropriate for (5)-(8) have already been introduced in previous works $[7,8,9]$. Regarding charged species, the number density of negative ions must be zero on the corona wire (cathode), since it is subjected to negative high voltage. On the contrary, positive ion density must vanish on the grounded cylinder (anode):

$$
\left.\begin{array}{ll}
N_{i}\left(r_{0}, z\right)=0, & \text { for negative ions, } \\
N_{i}(R, z)=0, & \text { for positive ions. }
\end{array}\right\}
$$

Furthermore, the time-averaged corona current measured in the experiments is used to build a boundary condition that involves the number densities of electrons and positive ions on the wire,

$$
I_{\exp }=2 \pi e_{0} r_{0} \sum_{i} \mu_{i} N_{i}\left(r_{0}, z\right) E\left(r_{0}, z\right) .
$$


This boundary condition has also been adopted by Wang and Chen in a recent publication [6]. The fact that the electron density on the wire is linked to the experimental current allows incorporating, indirectly, other processes that might alter the electron density and that are not explicitly included in the model, such as photoemission at the cathode.

At the inlet of the cylinder, the gas composition is pure oxygen, $\mathrm{O}_{2}$. Therefore, the number densities of all other neutral species is taken as zero,

$$
N_{j}(r, 0)=0 .
$$

On the surface of the wire and of the cylinder, two different situations can be found. On the one hand, the neutralization of ions gives rise to the generation of neutral species (e.g. $\mathrm{O}^{-}$is transformed into $\mathrm{O}$ on the anode). Therefore, the ion drift will be balanced by the molecular diffusion of the neutral species,

$$
e_{i} \mu_{i} N_{i} E-e_{0} D_{j} \frac{d N_{j}}{d r}=0, \text { at } r=r_{0} \text { and/or } r=R \text {, for all } z \text {. }
$$

However, the neutralization of $\mathrm{O}_{3}{ }^{-}$on the anode must also consider the possibility of ozone decomposition into molecular oxygen. This decomposition reaction is catalyzed by the presence of the electrode wall, and it is characterized by a certain decomposition coefficient, $\delta[21,7]$

$$
-D_{\mathrm{O}_{3}} \frac{d N_{\mathrm{O}_{3}}}{d r}=\delta N_{\mathrm{O}_{3}}+\mu_{\mathrm{O}_{3}^{-}} N_{\mathrm{O}_{3}^{-}} E, \quad \text { at } r=R .
$$

In this work, the value $\delta=2.88 \times 10^{-4} \mathrm{~cm} / \mathrm{s}$ will be taken as representative for stainless steel [22].

For the rest of neutral species, a zero diffusion flux is imposed on the wire and on the cylinder wall,

$$
D_{j} \frac{d N_{j}}{d r}=0, \text { at } r=r_{0} \text { and/or } r=R \text {, for all } z .
$$

Regarding the gas temperature, the cylinder surface is assumed to be at room temperature, since this electrode is in direct contact with the ambient air,

$$
T(R, z)=298 \mathrm{~K} .
$$

On the wire, a zero heat flux is imposed along the electrode,

$$
\frac{\partial T}{\partial r}=0, \quad \text { at } r=r_{0}, \text { for all } z .
$$

Finally, boundary conditions are imposed on the electrical potential. On the surface of the wire, the potential is equal to the applied voltage, while the cylinder is grounded,

$$
\phi\left(r_{0}\right)=V, \quad \phi(R)=0 .
$$

\subsection{Chemical kinetics model}

The chemical kinetics model used in this investigation is summarized in Table 1, and includes reactions between electrons, ions and neutral species, both in ground and in excited states. The selection of reactions is based on previous studies [7], in which a much more complete chemical model, with up to 97 reactions, was considered. The relevance of each reaction in the total chemical model was thoroughly investigated in these studies, and it was concluded that the number of reactions having a relative importance higher than $1 \%$ could be reduced to 38 , which are the ones retained in the present study. Certain plasma chemical processes, like electron-ion recombination or negative-positive ion recombination, have been omitted in the chemical model because they have a negligible contribution to the total gain/loss balance of electrons and ions. For example, let us consider electron-ion recombination of $\mathrm{O}_{2}{ }^{+}$. The principal reactions that participate in this process are 


$$
\begin{aligned}
\mathrm{e}+\mathrm{O}_{2}^{+}+\mathrm{O}_{2} & \rightarrow \mathrm{O}_{2}+\mathrm{O}_{2}, & & k \sim 10^{-26} \mathrm{~cm}^{6} / \mathrm{s} \\
\mathrm{e}+\mathrm{O}_{2}^{+} & \rightarrow \mathrm{O}+\mathrm{O}, & & k \sim 2 \times 10^{-7} \mathrm{~cm}^{3} / \mathrm{s} \\
& \rightarrow \mathrm{O}+\mathrm{O}\left({ }^{1} \mathrm{D}\right) & & k \sim 2 \times 10^{-7} \mathrm{~cm}^{3} / \mathrm{s}
\end{aligned}
$$

According to the results shown in figure 5, the maxima of electron and $\mathrm{O}_{2}{ }^{+}$densities are of the order of $10^{7} \mathrm{~cm}^{-3}$ and $10^{9} \mathrm{~cm}^{-3}$ respectively (these estimates can also be derived from the experimental current density). Therefore, the rate of e- $\mathrm{O}_{2}{ }^{+}$recombination is approximately,

$$
k \times[\mathrm{e}] \times\left[\mathrm{O}_{2}^{+}\right] \approx 6 \times 10^{9} \mathrm{~cm}^{-3} / \mathrm{s}
$$

However, the generation of $\mathrm{O}_{2}{ }^{+}$is governed by ionization,

$$
\mathrm{e}+\mathrm{O}_{2} \rightarrow \mathrm{O}_{2}^{+}+2 \mathrm{e} .
$$

The reaction rate constant of this process is electric-field dependent, and for $5 \mathrm{kV}$ its value is $k$ $\approx 5 \times 10^{-11} \mathrm{~cm}^{3} / \mathrm{s}$ at the position of the maximum electron density $(r \sim 0.03 \mathrm{~cm})$. Therefore, the rate of $\mathrm{O}_{2}^{+}$generation is about

$$
k \times[\mathrm{e}] \times\left[\mathrm{O}_{2}\right] \approx 10^{16} \mathrm{~cm}^{-3} / \mathrm{s} .
$$

In conclusion, the generation $\mathrm{O}_{2}{ }^{+}$is $10^{6}$ faster than their losses due to e- $\mathrm{O}_{2}{ }^{+}$recombination.

A similar estimate can be done for negative-positive ion recombination,

$$
\begin{array}{ll}
\mathrm{O}_{2}{ }^{+}+\mathrm{O}_{3}{ }^{-} \rightarrow \mathrm{O}_{2}+\mathrm{O}_{3}, & k \sim 2 \times 10^{-7} \mathrm{~cm}^{3} / \mathrm{s} \\
\mathrm{O}_{2}{ }^{+}+\mathrm{O}_{3}{ }^{-} \rightarrow 2 \mathrm{O}+\mathrm{O}_{3}, & k \sim 10^{-7} \mathrm{~cm}^{3} / \mathrm{s}
\end{array}
$$

Again, according to the results reported in figure 5, the rate of of recombination is given as

$$
k \times\left[\mathrm{O}_{2}^{+}\right] \times\left[\mathrm{O}_{3}^{-}\right] \approx 4 \times 10^{10} \mathrm{~cm}^{-3} / \mathrm{s}
$$

This value is significantly smaller than the rate of generation of $\mathrm{O}_{2}{ }^{+}$already reported $\left(\sim 10^{16} \mathrm{~cm}^{-}\right.$ $3 / \mathrm{s}$ ) or the rate of generation of $\mathrm{O}_{3}^{-}$, which occurs through electron transfer reaction

and whose magnitude is

$$
\mathrm{O}_{2}^{-}+\mathrm{O}_{3} \rightarrow \mathrm{O}_{2}+\mathrm{O}_{3}^{-}, \quad k \sim 8 \times 10^{-10} \mathrm{~cm}^{3} / \mathrm{s},
$$

$$
k \times\left[\mathrm{O}_{2}^{-}\right] \times\left[\mathrm{O}_{3}\right] \approx 2 \times 10^{15} \mathrm{~cm}^{-3} / \mathrm{s} .
$$

Therefore, the rates of generation of $\mathrm{O}_{2}{ }^{+}$and $\mathrm{O}_{3}{ }^{-}$are several orders of magnitude faster than the rate of positive-negative ion recombination.

On the contrary, other processes such as direct ionization, dissociative ionization, electronimpact dissociation, dissociative electron attachment, associative detachment, etc. are included in the chemical model through the most relevant reactions.

The temperature dependence of reaction rate constants has always been taken into account whenever it was available. Regarding electron driven reactions, their reaction rate constants depend on the reduced electric field, $E / N$, and the influence of the gas temperature is of secondary importance. 
Table 1. List of the chemical reactions used in the model of negative corona discharge in pure oxygen. Reaction rate constant are expressed in $\mathrm{cm}^{3} \mathrm{~s}^{-1}$ for two-body reactions, and in $\mathrm{cm}^{6} \mathrm{~s}^{-1}$ for three-body reactions. $T$ is the gas temperature in Kelvin. Source: Eliasson and Kogelschatz [23].

\begin{tabular}{|c|c|c|}
\hline no. & reaction & $\begin{array}{l}\text { reaction rate constants } \\
\left(\mathrm{cm}^{3} \mathrm{~s}^{-1} \text { or } \mathrm{cm}^{6} \mathrm{~s}^{-1}\right)\end{array}$ \\
\hline R1 & $\mathrm{e}+\mathrm{O}_{2} \rightarrow \mathrm{O}_{2}{ }^{+}+\mathrm{e}+\mathrm{e}$ & $f(E / N)$ \\
\hline $\mathrm{R} 2$ & $\mathrm{e}+\mathrm{O}_{2} \rightarrow \mathrm{O}^{-}+\mathrm{O}$ & $f(E / N)$ \\
\hline $\mathrm{R} 3$ & $\mathrm{e}+\mathrm{O}_{2}+\mathrm{O}_{2} \rightarrow \mathrm{O}_{2}^{-}+\mathrm{O}_{2}$ & $f(E / N)$ \\
\hline R4 & $\mathrm{e}+\mathrm{O}_{3} \rightarrow \mathrm{O}_{2}^{-}+\mathrm{O}$ & $f(E / N)$ \\
\hline R5 & $\mathrm{e}+\mathrm{O}_{3} \rightarrow \mathrm{O}^{-}+\mathrm{O}_{2}$ & $f(E / N)$ \\
\hline R6 & $\mathrm{e}+\mathrm{O}_{3} \rightarrow \mathrm{O}_{3}^{+}+2 \mathrm{e}$ & $f(E / N)$ \\
\hline R7 & $\mathrm{e}+\mathrm{O}_{2} \rightarrow \mathrm{O}^{+}+\mathrm{O}+2 \mathrm{e}$ & $f(E / N)$ \\
\hline $\mathrm{R} 8$ & $\mathrm{e}+\mathrm{O}_{2} \rightarrow \mathrm{O}+\mathrm{O}+\mathrm{e}$ & $f(E / N)$ \\
\hline R9 & $\mathrm{e}+\mathrm{O}_{2} \rightarrow \mathrm{O}+\mathrm{O}\left({ }^{1} \mathrm{D}\right)+\mathrm{e}$ & $f(E / N)$ \\
\hline $\mathrm{R} 10$ & $\mathrm{e}+\mathrm{O}_{3} \rightarrow \mathrm{O}+\mathrm{O}_{2}+\mathrm{e}$ & $f(E / N)$ \\
\hline $\mathrm{R} 11$ & $\mathrm{e}+\mathrm{O}_{2} \rightarrow \mathrm{O}_{2}\left({ }^{1} \Delta_{\mathrm{g}}\right)+\mathrm{e}$ & $f(E / N)$ \\
\hline $\mathrm{R} 12$ & $\mathrm{e}+\mathrm{O}_{2} \rightarrow \mathrm{O}_{2}\left({ }^{1} \Sigma_{\mathrm{g}}^{+}\right)+\mathrm{e}$ & $f(E / N)$ \\
\hline $\mathrm{R} 13$ & $\mathrm{e}+\mathrm{O}_{2} \rightarrow \mathrm{e}+\mathrm{O}_{2}{ }^{*}$ & $f(E / N)$ \\
\hline $\mathrm{R} 14$ & $\mathrm{e}+\mathrm{O}_{3} \rightarrow \mathrm{O}\left({ }^{1} \mathrm{D}\right)+\mathrm{O}_{2}\left({ }^{1} \Delta_{\mathrm{g}}\right)+\mathrm{e}$ & $f(E / N)$ \\
\hline $\mathrm{R} 15$ & $\mathrm{e}+\mathrm{O}_{3} \rightarrow \mathrm{O}^{+}+\mathrm{O}+\mathrm{O}+2 \mathrm{e}$ & $f(E / N)$ \\
\hline R16 & $\mathrm{O}^{-}+\mathrm{O}_{2} \rightarrow \mathrm{O}+\mathrm{O}_{2}+\mathrm{e}$ & $f(E / N)$ \\
\hline $\mathrm{R} 17$ & $\mathrm{O}^{-}+\mathrm{O}_{2} \rightarrow \mathrm{O}_{2}^{-}+\mathrm{O}$ & $f(E / N)$ \\
\hline $\mathrm{R} 18$ & $\mathrm{O}_{2}^{-}+\mathrm{O}_{3} \rightarrow \mathrm{O}_{3}^{-}+\mathrm{O}_{2}$ & $7.8 \times 10^{-10}$ \\
\hline $\mathrm{R} 19$ & $\mathrm{O}^{-}+\mathrm{O}_{3} \rightarrow \mathrm{O}_{3}^{-}+\mathrm{O}$ & $5.3 \times 10^{-10}$ \\
\hline $\mathrm{R} 20$ & $\mathrm{O}^{-}+\mathrm{O}_{2}+\mathrm{O}_{2} \rightarrow \mathrm{O}_{3}^{-}+\mathrm{O}_{2}$ & $1.1 \times 10^{-30}(300 / T)$ \\
\hline $\mathrm{R} 21$ & $\mathrm{O}^{+}+\mathrm{O}_{2} \rightarrow \mathrm{O}_{2}^{+}+\mathrm{O}$ & $2 \times 10^{-11}(T / 300)^{-0.5}$ \\
\hline $\mathrm{R} 22$ & $\mathrm{O}_{3}+\mathrm{O}_{2} \rightarrow \mathrm{O}+\mathrm{O}_{2}+\mathrm{O}_{2}$ & $7.26 \times 10^{-10} \exp (-11400 / T)$ \\
\hline $\mathrm{R} 23$ & $\mathrm{O}+\mathrm{O}_{3} \rightarrow \mathrm{O}_{2}+\mathrm{O}_{2}$ & $1.8 \times 10^{-11} \exp (-2300 / T)$ \\
\hline $\mathrm{R} 24$ & $\mathrm{O}+\mathrm{O}_{3} \rightarrow \mathrm{O}_{2}\left({ }^{1} \Delta_{\mathrm{g}}\right)+\mathrm{O}_{2}$ & $10^{-11} \exp (-2300 / T)$ \\
\hline $\mathrm{R} 25$ & $\mathrm{O}+\mathrm{O}_{2}+\mathrm{O}_{2} \rightarrow \mathrm{O}_{3}+\mathrm{O}_{2}$ & $6.4 \times 10^{-35} \exp (-663 / T)$ \\
\hline $\mathrm{R} 26$ & $\mathrm{O}+\mathrm{O}_{2}+\mathrm{O}_{3} \rightarrow \mathrm{O}_{3}+\mathrm{O}_{3}$ & $1.45 \times 10^{-34} \exp (-663 / T)$ \\
\hline $\mathrm{R} 27$ & $\mathrm{O}_{2}\left({ }^{1} \Delta_{\mathrm{g}}\right)+\mathrm{O}_{3} \rightarrow \mathrm{O}_{2}+\mathrm{O}_{2}+\mathrm{O}\left({ }^{1} \mathrm{D}\right)$ & $10^{-11}$ \\
\hline $\mathrm{R} 28$ & $\mathrm{O}\left({ }^{1} \mathrm{D}\right)+\mathrm{O}_{3} \rightarrow \mathrm{O}_{2}+\mathrm{O}+\mathrm{O}$ & $1.2 \times 10^{-10}$ \\
\hline R29 & $\mathrm{O}\left({ }^{1} \mathrm{D}\right)+\mathrm{O}_{3} \rightarrow \mathrm{O}_{2}\left({ }^{1} \Delta_{\mathrm{g}}\right)+\mathrm{O}_{2}$ & $2.7 \times 10^{-10}$ \\
\hline $\mathrm{R} 30$ & $\mathrm{O}\left({ }^{1} \mathrm{D}\right)+\mathrm{O}_{3} \rightarrow \mathrm{O}_{2}\left({ }^{1} \Delta_{\mathrm{g}}\right)+\mathrm{O}_{2}\left({ }^{1} \Delta_{\mathrm{g}}\right)$ & $2.5 \times 10^{-10}$ \\
\hline $\mathrm{R} 31$ & $\mathrm{O}\left({ }^{1} \mathrm{D}\right)+\mathrm{O}_{3} \rightarrow \mathrm{O}+\mathrm{O}_{3}$ & $2.5 \times 10^{-10}$ \\
\hline $\mathrm{R} 32$ & $\mathrm{O}\left({ }^{1} \mathrm{D}\right)+\mathrm{O}_{3} \rightarrow \mathrm{O}_{2}+\mathrm{O}_{2}\left({ }^{1} \Sigma_{\mathrm{g}}^{+}\right)$ & $4.0 \times 10^{-11}$ \\
\hline R33 & $\mathrm{O}_{2}\left({ }^{1} \Sigma_{\mathrm{g}}^{+}\right)+\mathrm{O}_{3} \rightarrow \mathrm{O}_{2}+\mathrm{O}_{3}$ & $2.2 \times 10^{-11}$ \\
\hline R34 & $\mathrm{O}_{2}\left({ }^{1} \Sigma_{\mathrm{g}}^{+}\right)+\mathrm{O}_{3} \rightarrow \mathrm{O}_{2}+\mathrm{O}_{2}+\mathrm{O}$ & $1.5 \times 10^{-11}$ \\
\hline R35 & $\mathrm{O}_{2}\left({ }^{1} \Sigma_{\mathrm{g}}^{+}\right)+\mathrm{O}_{2} \rightarrow \mathrm{O}_{2}+\mathrm{O}_{2}\left({ }^{1} \Delta_{\mathrm{g}}\right)$ & $3.97 \times 10^{-17}$ \\
\hline R36 & $\mathrm{O}_{2}^{*}+\mathrm{O}_{3} \rightarrow \mathrm{O}_{2}+\mathrm{O}_{3}^{*}$ & $3.0 \times 10^{-11}$ \\
\hline R37 & $\mathrm{O}_{3}^{*}+\mathrm{O}_{2} \rightarrow \mathrm{O}_{2}+\mathrm{O}_{3}$ & $2.0 \times 10^{-14}$ \\
\hline R38 & $\mathrm{O}\left({ }^{1} \mathrm{D}\right)+\mathrm{O}_{2} \rightarrow \mathrm{O}+\mathrm{O}_{2}\left({ }^{1} \Sigma_{\mathrm{g}}{ }^{+}\right)$ & $2.56 \times 10^{-11} \exp (-67 / T)$ \\
\hline
\end{tabular}



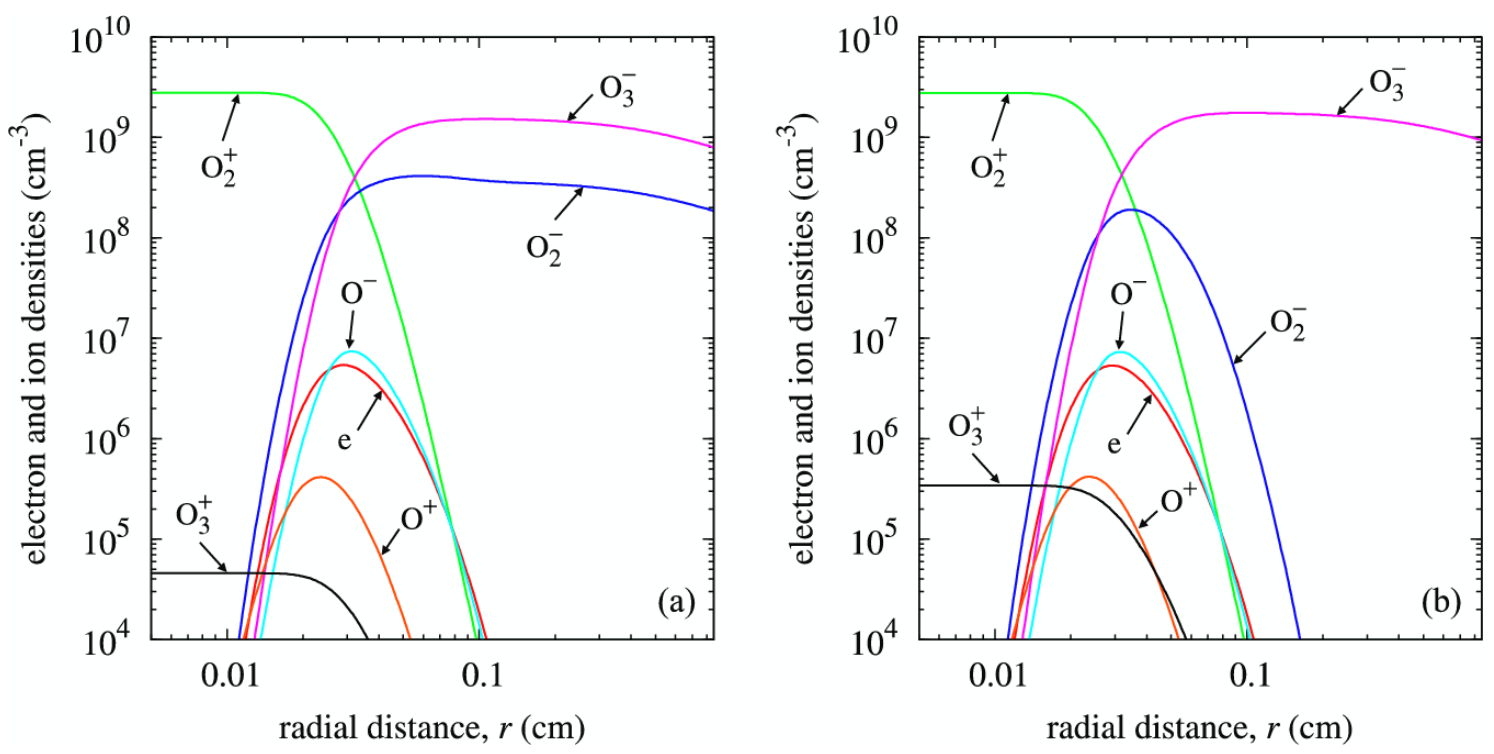

Figure 5: Radial distribution of the electrons and ions at $z=10^{-2} \mathrm{~cm}$ (a) and at $z=5 \mathrm{~cm}$ (b), for $V=5 \mathrm{kV}$, $Q=200 \mathrm{~cm}^{3} / \mathrm{min}$ and $R=0.85 \mathrm{~cm}$.

\section{Results and discussion}

Numerical simulations and experiments of negative corona discharge were carried out for different values of the applied voltage, gas flow rate $\left(100-200 \mathrm{~cm}^{3} / \mathrm{s}\right)$ and cylinder radius $(0.65$, 0.85 and $1.1 \mathrm{~cm})$. However, for the sake of brevity, the 2D-spatial distribution of charge and neutral species will be only presented for the case $V=5 \mathrm{kV}, Q=200 \mathrm{~cm}^{3} / \mathrm{s}$ and $R=0.85 \mathrm{~cm}$. For other values of the $V, Q$ and $R$, the spatial distribution of species is qualitatively similar but, of course, quantitatively different. Therefore, in the subsequent subsections, the influence of these parameters will be presented, with a special emphasis on ozone generation.

\subsection{Distribution of charged particles}

Figure 5 shows the radial distribution of charged species at a distance $z=0.01 \mathrm{~cm}$ from the gas inlet (fig. 5a) and at the exit of the cylinder, $z=5 \mathrm{~cm}$ (fig. 5b). The structure of the electrical discharge is almost identical to the case of zero-flow rate [8], that is, the inter-electrode space appears divided in three regions: the ionization region, around of the cathode; the active region, where the electron density is maximum; and drift region, where the negative space charge accumulates. The transport of charge in the drift region is entirely due to $\mathrm{O}_{2}^{-}$and $\mathrm{O}_{3}{ }^{-}$. Negative oxygen ions, $\mathrm{O}^{-}$, are absent from this region due to the existence of electron transfer reactions (R17), (R19) and (R20). An analogous situation is found in the ionization region, where $\mathrm{O}^{+}$is converted into $\mathrm{O}_{2}^{+}$through reaction (R21).

At other values of the axial coordinate $z$, the radial distribution of electrons and some ions $\left(\mathrm{O}_{2}{ }^{+}\right.$, $\mathrm{O}^{+}$and $\mathrm{O}^{-}$) is very similar. The reason for this similarity resides in that these species are mainly generated and disappear in reactions with oxygen molecules, e.g. (R1), (R2), (R7), (R17), (R20) and (R21). Since the concentration of oxygen molecules is negligibly affected by the electrical discharge, the rate of generation/decomposition of these species and, therefore, their stationary number densities are independent of the distance along the wire.

On the contrary, the densities of $\mathrm{O}_{3}{ }^{+}, \mathrm{O}_{2}{ }^{-}$and $\mathrm{O}_{3}{ }^{-}$exhibit substantial changes in the axial direction, as can be readily seen in figure $5 \mathrm{~b}$, and in figures 6 to 8 , where the $2 \mathrm{D}$-spatial distributions of these species has been presented. These species have in common that their chemical kinetics is linked to ozone. For example, negative ozone ions are generated through the reaction

$$
\mathrm{O}_{2}^{-}+\mathrm{O}_{3} \rightarrow \mathrm{O}_{3}^{-}+\mathrm{O}_{2}
$$




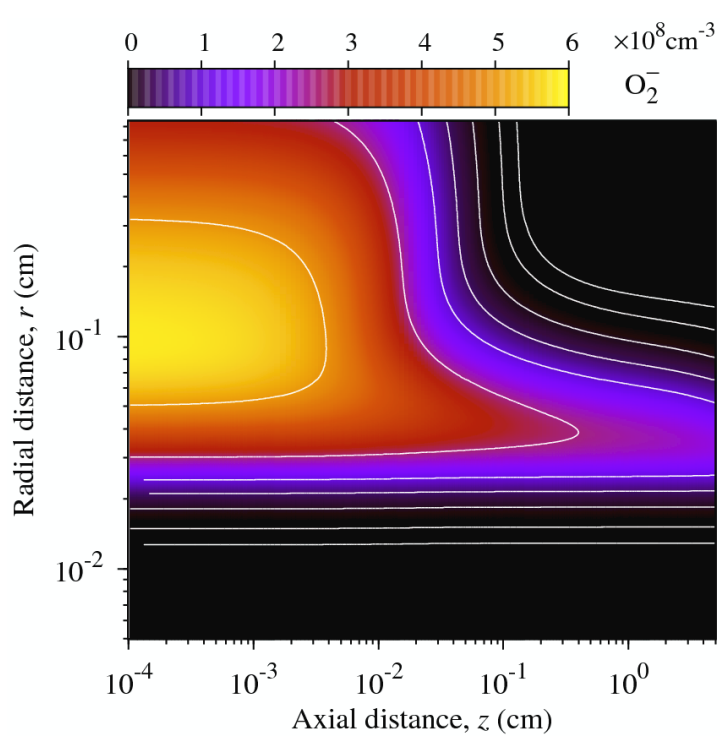

Figure 6. 2D-spatial distribution of $\mathrm{O}_{2}^{-}$ions corresponding to $5 \mathrm{kV}$ and $200 \mathrm{~cm}^{3} / \mathrm{min}$. Contour lines are drawn at $10^{5}, 10^{6}, 10^{7}, 4 \times 10^{7}, 10^{8}$, $2.5 \times 10^{8}$ and $5 \times 10^{8} \mathrm{~cm}^{-3}$.

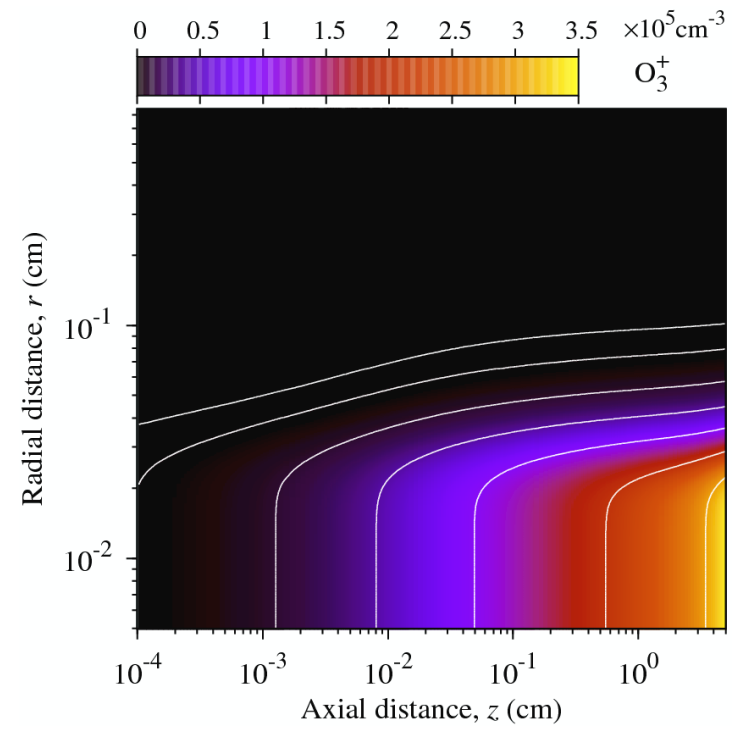

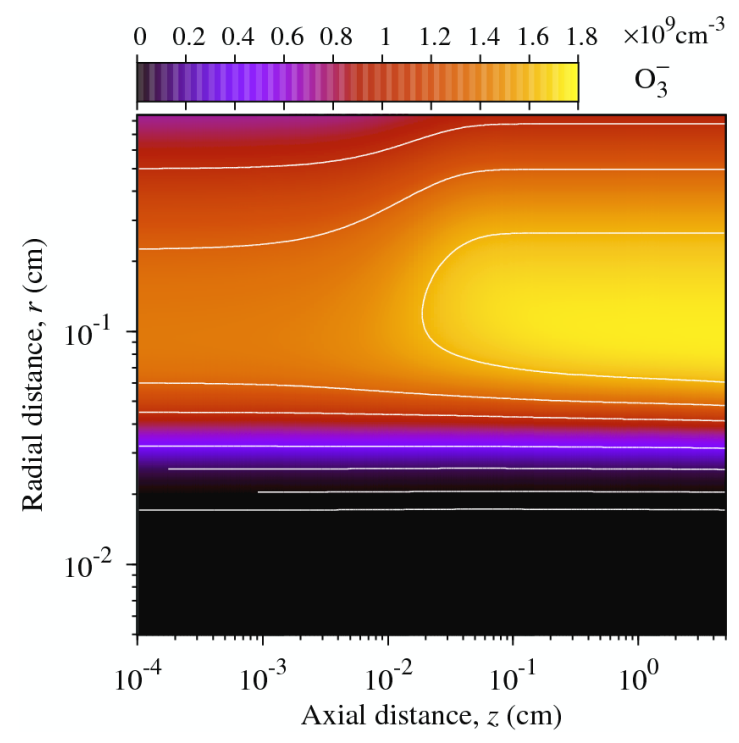

Figure 7. 2D-spatial distribution of $\mathrm{O}_{3}^{-}$ions corresponding to $5 \mathrm{kV}$ and $200 \mathrm{~cm}^{3} / \mathrm{min}$. Contour lines are drawn at $10^{6}, 10^{7}, 10^{8}, 4 \times 10^{8}, 10^{9}$, $1.3 \times 10^{9}$ and $1.6 \times 10^{9} \mathrm{~cm}^{-3}$.

Figure 8. 2D-spatial distribution of $\mathrm{O}_{3}{ }^{+}$ions corresponding to $5 \mathrm{kV}$ and $200 \mathrm{~cm}^{3} / \mathrm{min}$. Contour lines are drawn at $10^{2}, 10^{3}, 10^{4}, 4 \times 10^{4}, 10^{5}$, $2 \times 10^{5}$ and $3 \times 10^{5} \mathrm{~cm}^{-3}$.

which, in turn, constitutes an important sink of $\mathrm{O}_{2}^{-}$. The rate of conversion of $\mathrm{O}_{2}^{-}$into $\mathrm{O}_{3}^{-}$ augments in the direction of the flow since, as it will be shown in section 4.2, ozone density also increases in such direction. Therefore, as the gas flows through the corona reactor, $\mathrm{O}_{2}{ }^{-}$tends to disappear (figure 6) and to be converted into $\mathrm{O}_{3}{ }^{-}$(figure 7). At the exit of the cylinder (fig. 5b) the distribution of ions is similar to that found under flow-stopped conditions [7,8], that is, $\mathrm{O}_{2}{ }^{-}$ ions are completely absent from the drift region. However, in the vicinity of the inlet of the gas, where ozone concentration is low, $\mathrm{O}_{2}{ }^{-}$and $\mathrm{O}_{3}{ }^{-}$densities possess similar magnitudes, as shown in figure $5 \mathrm{a}$.

A similar effect is also observed for $\mathrm{O}_{3}{ }^{+}$(figure 8), which is generated by ionization of ozone molecules. Its number density grows with the axial distance to the gas inlet, as ozone density does. 

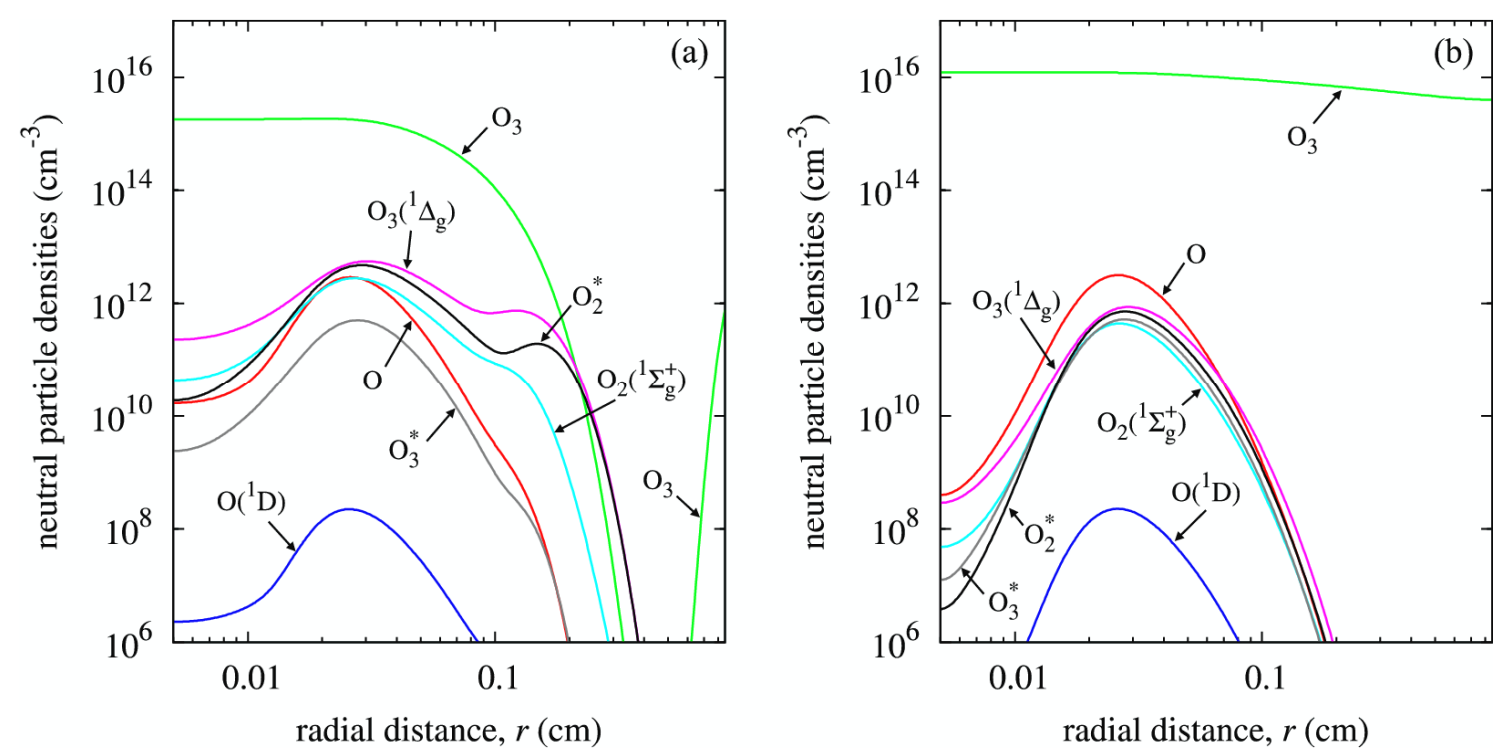

Figure 9: Radial distribution of neutral species at $z=10^{-2} \mathrm{~cm}$ (a) and at $z=5 \mathrm{~cm}$ (b), for $V=5 \mathrm{kV}$, $Q=200 \mathrm{~cm}^{3} / \mathrm{min}$ and $R=0.85 \mathrm{~cm}$.

\subsection{Distribution of neutral particles}

Figure 9 shows the radial distribution of neutral species at $z=0.01 \mathrm{~cm}$ (fig. $9 \mathrm{a}$ ) and at $z=5 \mathrm{~cm}$ (fig. 9b), for the case $V=5 \mathrm{kV}$ and $Q=200 \mathrm{~cm}^{3} / \mathrm{s}$, according to the numerical simulation. The two-dimensional spatial distribution of neutral species, for the same parameters, is shown in Figures 10-16. Clearly, there is an significant evolution of the distribution of species as the gas flows along the cylinder.

Oxygen atoms are confined to the region where the electron density is significant, that is, the active region of the corona discharge (figure 10). This is so because this species is mainly produced by electron impact with oxygen molecules,

$$
\begin{aligned}
\mathrm{e}+\mathrm{O}_{2} & \rightarrow \mathrm{O}+\mathrm{O}+\mathrm{e}, \\
& \rightarrow \mathrm{O}+\mathrm{O}\left({ }^{1} \mathrm{D}\right)+\mathrm{e},
\end{aligned}
$$

and it is consumed in the generation of ozone molecules via a three body reaction with oxygen,

$$
\mathrm{O}+\mathrm{O}_{2}+\mathrm{O}_{2} \rightarrow \mathrm{O}_{3}+\mathrm{O}_{2} \text {. }
$$

Since $\mathrm{O}_{2}$ concentration in weakly affected by the electrical discharge, the source and sink rates of oxygen atoms are constant along the axial direction. In addition, the characteristic lifetime of oxygen atoms, $\tau_{k} \sim\left(k_{25}\left[\mathrm{O}_{2}\right]^{2}\right)^{-1} \sim 2 \times 10^{-4} \mathrm{~s}$, is very short compared with diffusion time in the radial direction, $\tau_{D} \sim R^{2} / D \sim 3 \mathrm{~s}$, or the residence time of the gas inside the cylinder, $\tau_{z} \sim L / v_{z} \sim 3$ s. Therefore, radial diffusion and advection of oxygen atoms in the direction of the flow are negligible. However, a slight increase of $\mathrm{O}$ with the axial distance can be observed in figure 10 . This increase is possibly linked to the growth of ozone density along the cylinder, which favours the formation of oxygen atoms through (R10), (R28) and (R31).

Ozone density distribution (figure 11) is more complex. At the inlet of the gas $\left(z<10^{-3}-10^{-2}\right.$ $\mathrm{cm}$ ), ozone molecules are concentrated in the active region of the electrical discharge, where they are being generated according to (R25). In the drift region, its number density is still low, because the molecules have not had enough time to diffuse in the radial direction, towards the anode. However, the neutralization of $\mathrm{O}_{3}{ }^{-}$ions at the anode gives rise to a sharp increase of ozone at the surface of this electrode (see fig. 9a). As the gas flows towards the exit, molecular diffusion tends to reduce the radial gradient of density, and there is a growth in concentration in the axial direction due to the advection of ozone. Reaction (R27) between ozone and $\mathrm{O}_{2}\left({ }^{1} \Delta_{\mathrm{g}}\right)$ 
constitutes the most important sink of $\mathrm{O}_{3}$ and, consequently, the lifetime of ozone is linked to the concentration of $\mathrm{O}_{2}\left({ }^{1} \Delta_{\mathrm{g}}\right)$. For $z>0.01 \mathrm{~cm}$, it is $\tau_{k} \sim\left(k_{27}\left[\mathrm{O}_{2}\left({ }^{1} \Delta_{\mathrm{g}}\right)\right]\right)^{-1}>1 \mathrm{~s}$, which is similar to or longer than the radial diffusion and residence characteristic time $\left(\tau_{z} \sim 3 \mathrm{~s}\right)$. Therefore, contrary to the other species, diffusion and advection have a strong influence on ozone distribution.

The spatial distribution of $\mathrm{O}_{2}\left({ }^{1} \Delta_{\mathrm{g}}\right), \mathrm{O}_{2}\left({ }^{1} \Sigma_{\mathrm{g}}{ }^{+}\right)$and $\mathrm{O}_{2}{ }^{*}$ resemble each other (figures 12, 13 and 14), thus indicating that these species probably share a similar chemical kinetics. Indeed, the formation of these species occurs primarily through electron-impact reactions with molecular oxygen, (R11), (R12) and (R13). In the case of $\mathrm{O}_{2}\left({ }^{1} \Sigma_{\mathrm{g}}^{+}\right)$, there is also a significant possibility of formation in collisions between $\mathrm{O}_{2}$ and $\mathrm{O}\left({ }^{1} \mathrm{D}\right)$ (reaction (R38)). The three species also share the same loss process: collisions with ozone molecules. Therefore, at the inlet of the gas, where ozone concentration is still low, generation dominates over losses, and $\mathrm{O}_{2}\left({ }^{1} \Delta_{\mathrm{g}}\right), \mathrm{O}_{2}\left({ }^{1} \Sigma_{\mathrm{g}}{ }^{+}\right)$and $\mathrm{O}_{2}{ }^{*}$ start to form around the active region of the electrical discharge. The advection of the gas makes the number density of theses species to grow in the direction of the flow. As the concentration of ozone rises, these excited species start being quickly destroyed in reactions with ozone,

$$
\begin{gathered}
\mathrm{O}_{2}\left({ }^{1} \Delta_{\mathrm{g}}\right)+\mathrm{O}_{3} \rightarrow \mathrm{O}_{2}+\mathrm{O}_{2}+\mathrm{O}\left({ }^{1} \mathrm{D}\right), \\
\mathrm{O}_{2}\left({ }^{1} \Sigma_{\mathrm{g}}^{+}\right)+\mathrm{O}_{3} \rightarrow \mathrm{O}_{2}+\mathrm{O}_{3}, \\
\mathrm{O}_{2}\left({ }^{1} \Sigma_{\mathrm{g}}{ }^{+}\right)+\mathrm{O}_{3} \rightarrow \mathrm{O}_{2}+\mathrm{O}_{2}+\mathrm{O} \\
\mathrm{O}_{2}{ }^{*}+\mathrm{O}_{3} \rightarrow \mathrm{O}_{2}+\mathrm{O}_{3}{ }^{*}
\end{gathered}
$$

Thus, their number densities go through a maximum and then decline with the coordinate $z$. Due to their short lifetime, these species always remain confined within the active region.

Similarly to oxygen atoms, the excited species $\mathrm{O}\left({ }^{1} \mathrm{D}\right)$ is formed by electron impact with oxygen molecules,

$$
\mathrm{e}+\mathrm{O}_{2} \rightarrow \mathrm{O}+\mathrm{O}\left({ }^{1} \mathrm{D}\right)+\mathrm{e}
$$

and it is destroyed in collisions with $\mathrm{O}_{2}$

$$
\mathrm{O}\left({ }^{1} \mathrm{D}\right)+\mathrm{O}_{2} \rightarrow \mathrm{O}+\mathrm{O}_{2}\left({ }^{1} \Sigma_{\mathrm{g}}^{+}\right) \text {. }
$$

The lifetime of these excited atoms is very short $\left(\tau_{\mathrm{\kappa}} \sim\left(k_{38}\left[\mathrm{O}_{2}\right]\right)^{-1} \sim 2 \mathrm{~ns}\right)$. Therefore, their spatial distribution should be unaffected by molecular diffusion or advection (figure 14). However, oxygen-excited species have some influence on the stationary density of $\mathrm{O}\left({ }^{1} \mathrm{D}\right)$. Particularly, ozone decomposition by $\mathrm{O}_{2}\left({ }^{1} \Delta_{\mathrm{g}}\right)$ (reaction (R27)) constitutes an additional source of $\mathrm{O}\left({ }^{1} \mathrm{D}\right)$, and its effect can be observed as an increase of its number density at $z \sim 10^{-3} \mathrm{~cm}$.

Finally, vibrationaly-excited ozone molecules, $\mathrm{O}_{3}{ }^{*}$, are formed from the de-excitation of $\mathrm{O}_{2}{ }^{*}$ with ozone,

$$
\mathrm{O}_{2}{ }^{*}+\mathrm{O}_{3} \rightarrow \mathrm{O}_{2}+\mathrm{O}_{3}{ }^{*}
$$

and the reactant $\mathrm{O}_{2}{ }^{*}$ is generated in electron-impact reactions with molecular oxygen,

$$
\mathrm{e}+\mathrm{O}_{2} \rightarrow \mathrm{e}+\mathrm{O}_{2}{ }^{*} \text {. }
$$

Since the reaction rate of this last process is slower than that of (R36), the rate of generation of $\mathrm{O}_{3}{ }^{*}$ is limited by (R13). On the other hand, de-excitation of $\mathrm{O}_{3}{ }^{*}$ occurs in collisions with molecular oxygen (reaction (R37)). Therefore, both the generation and sink of $\mathrm{O}_{3}{ }^{*}$ are controlled by reactions that involve, mainly, electrons and $\mathrm{O}_{2}$, which are constant along the axial direction. This fact, together with the short lifetime of $\mathrm{O}_{3}{ }^{*}$, explain that this species is spatially localized in the active region of the corona, and homogenously distributed in the direction of the flow (figure 16). It is only at the entry of the cylinder, where ozone concentration is still very low, that reaction (R36) limits the formation of $\mathrm{O}_{3}{ }^{*}$. In that region, $\mathrm{O}_{3}{ }^{*}$ increases with $z$ as ozone does too.

The gas temperature distribution is shown in figure 17. Heat generation is localized around the wire, where $E J_{\text {ion }}$ is maximum, but thermal conduction and gas advection propagate the thermal 
Numerical simulation of an oxygen-fed wire-to-cylinder negative corona discharge in the glow regime

energy in the radial and axial direction, respectively. At the exit of the cylinder, the temperature of the gas around the wire has increased about $20^{\circ} \mathrm{C}$. 


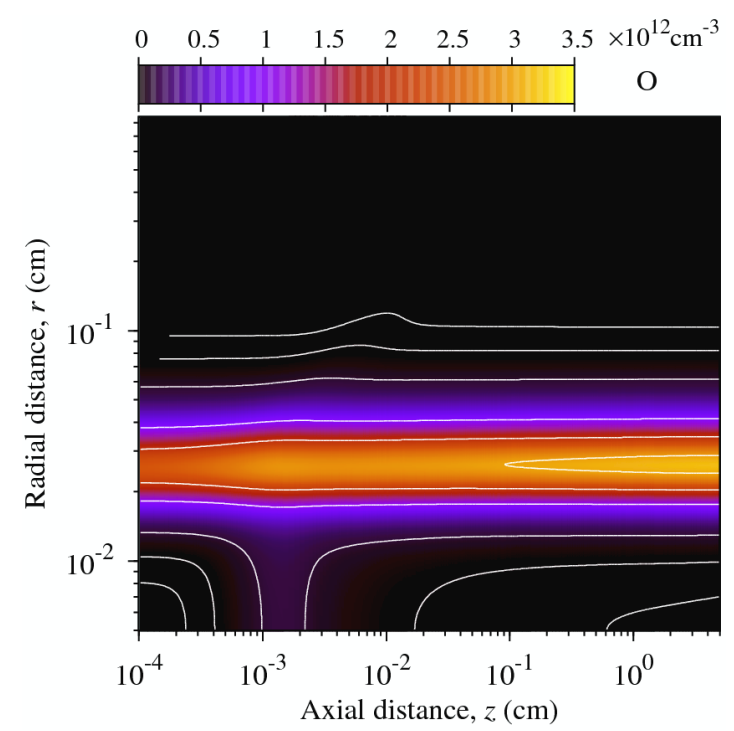

Figure 10. 2D-spatial distribution of oxygen atoms corresponding to $5 \mathrm{kV}$ and $200 \mathrm{~cm}^{3} / \mathrm{min}$. Contour lines are drawn at $10^{9}, 10^{10}, 10^{11}, 10^{12}$, $2 \times 10^{12}$ and $3 \times 10^{12} \mathrm{~cm}^{-3}$.

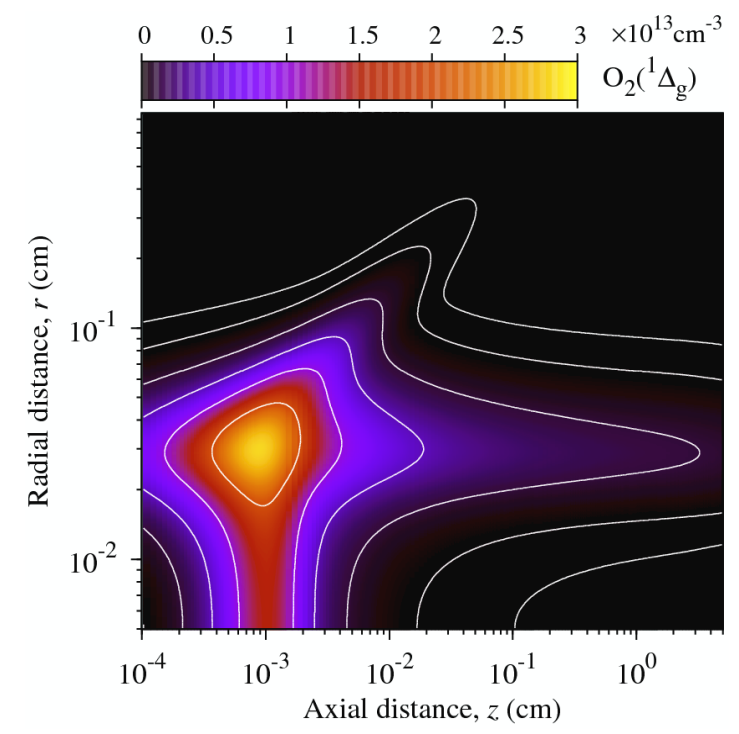

Figure 12. 2D-spatial distribution of metastable oxygen molecule $\mathrm{O}_{2}\left({ }^{1} \Delta_{\mathrm{g}}\right)$ corresponding to $5 \mathrm{kV}$ and $200 \mathrm{~cm}^{3} / \mathrm{min}$. Contour lines are drawn at $10^{10}, 10^{11}, 10^{12}, 4 \times 10^{12}, 10^{13}$ and $2 \times 10^{13} \mathrm{~cm}^{-3}$.

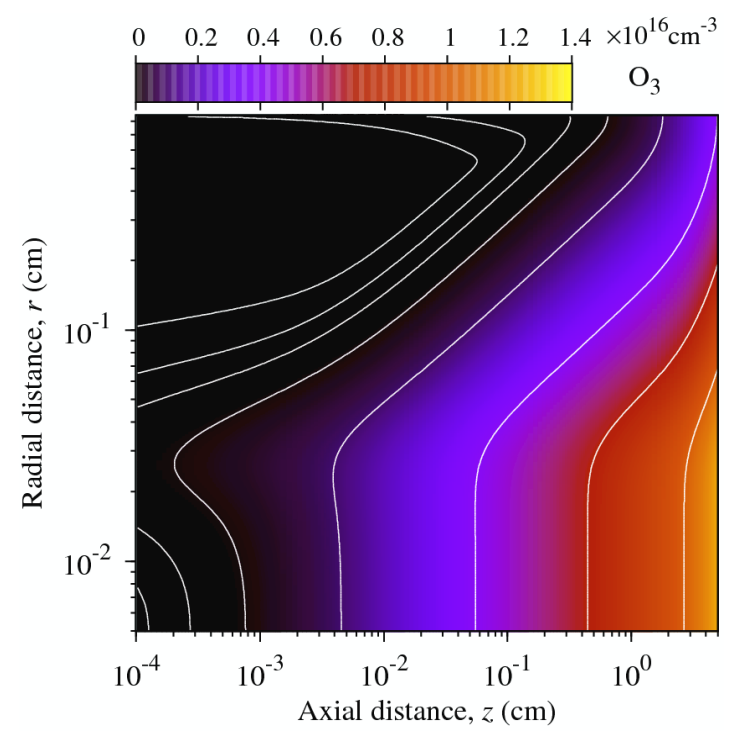

Figure 11. 2D-spatial distribution of ozone corresponding to $5 \mathrm{kV}$ and $200 \mathrm{~cm}^{3} / \mathrm{min}$. Contour lines are drawn at $10^{10}, 10^{12}, 10^{13}, 10^{14}, 10^{15}$, $4 \times 10^{15}, 7 \times 10^{15}$ and $10^{16} \mathrm{~cm}^{-3}$.

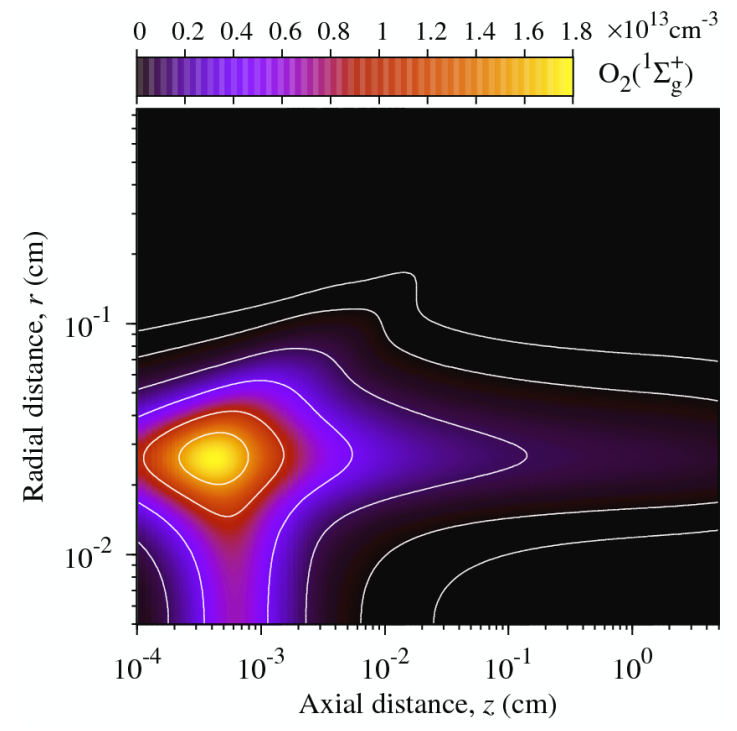

Figure 13. 2D-spatial distribution of metastable oxygen molecule $\mathrm{O}_{2}\left({ }^{1} \Sigma_{\mathrm{g}}{ }^{+}\right)$corresponding to $5 \mathrm{kV}$ and $200 \mathrm{~cm}^{3} / \mathrm{min}$. Contour lines are drawn at $10^{10}, 10^{11}, 10^{12}, 4 \times 10^{12}, 10^{13}$ and $1.5 \times 10^{13} \mathrm{~cm}^{-3}$. 


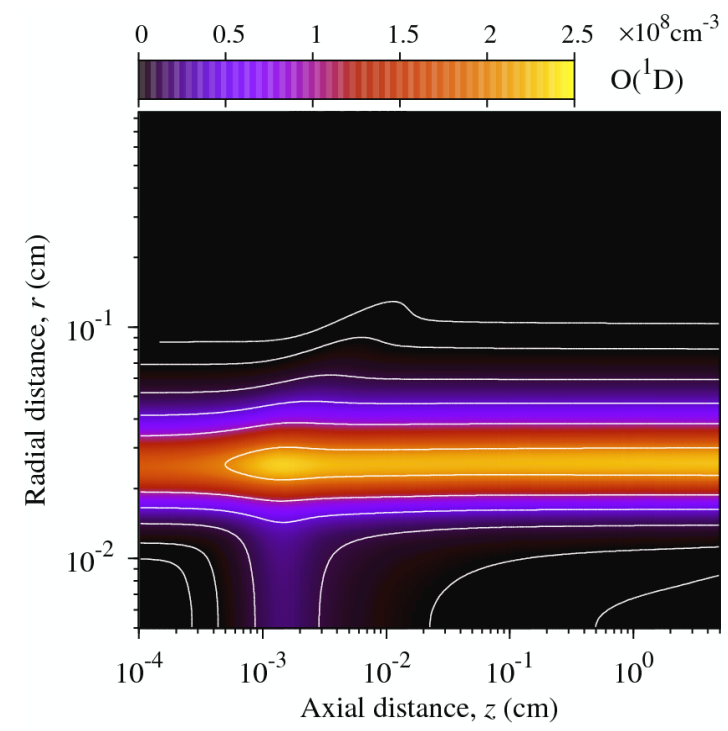

Figure 14. 2D-spatial distribution of metastable oxygen atom $\mathrm{O}\left({ }^{1} \mathrm{D}\right)$ corresponding to $5 \mathrm{kV}$ and $200 \mathrm{~cm}^{3} / \mathrm{min}$. Contour lines are drawn at $10^{5}$, $10^{6}, 10^{7}, 4 \times 10^{7}, 10^{8}$ and $2 \times 10^{8} \mathrm{~cm}^{-3}$.

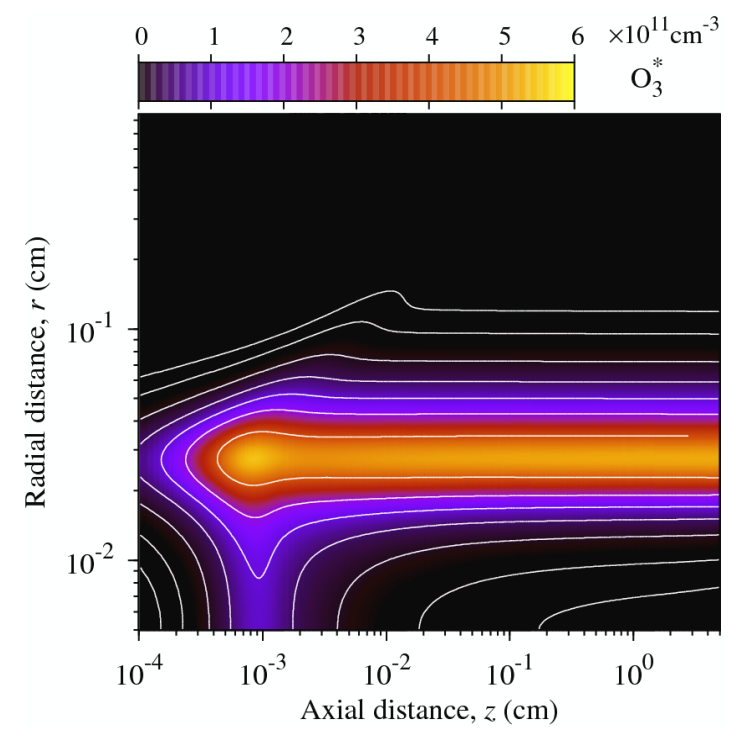

Figure 16. 2D-spatial distribution of vibrationally excited ozone $\mathrm{O}_{3}{ }^{*}$ corresponding to $5 \mathrm{kV}$ and 200 $\mathrm{cm}^{3} / \mathrm{min}$. Contour lines are drawn at $10^{8}, 10^{9}$, $10^{10}, 4 \times 10^{10}, 10^{11}, 2 \times 10^{11}$ and $4 \times 10^{11} \mathrm{~cm}^{-3}$.

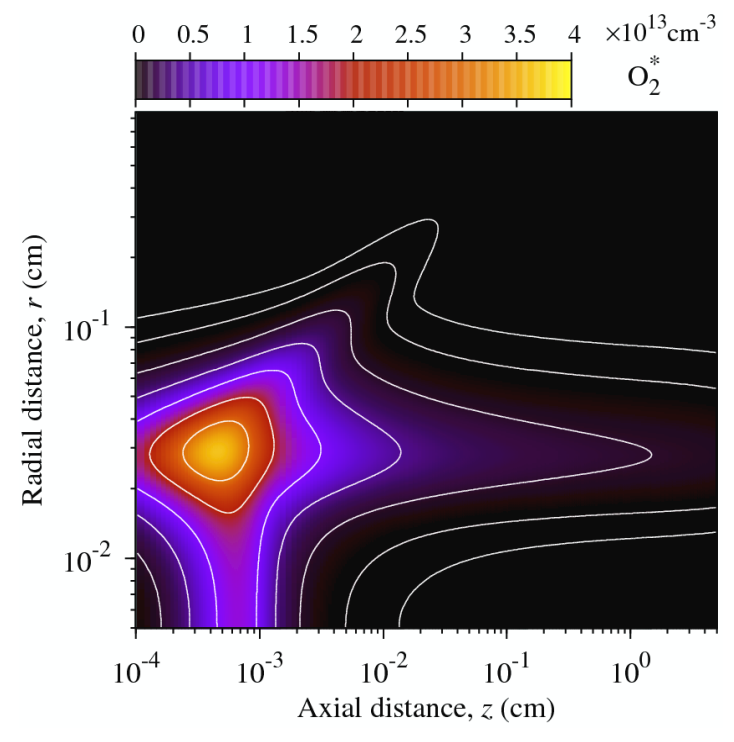

Figure 15. 2D-spatial distribution of vibrationally excited oxygen molecule $\mathrm{O}_{2}{ }^{*}$ corresponding to 5 $\mathrm{kV}$ and $200 \mathrm{~cm}^{3} / \mathrm{min}$. Contour lines are drawn at $10^{10}, 10^{11}, 10^{12}, 4 \times 10^{12}, 10^{13}, 2 \times 10^{13}$ and $3 \times 10^{13}$ $\mathrm{cm}^{-3}$.

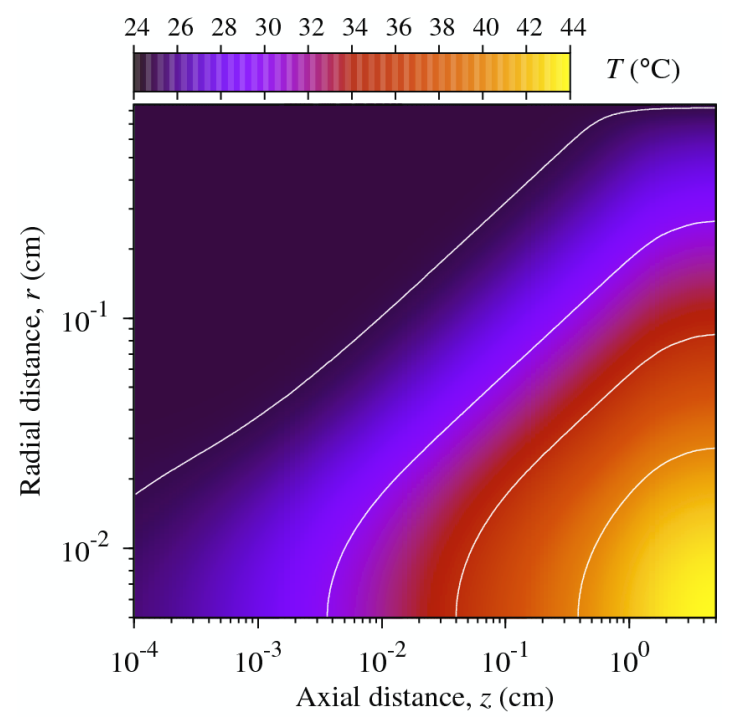

Figure 17. 2D-spatial temperature distribution corresponding to $5 \mathrm{kV}$ and $200 \mathrm{~cm}^{3} / \mathrm{min}$. Contour lines are drawn at $25,30,35$ and $40{ }^{\circ} \mathrm{C}$. 


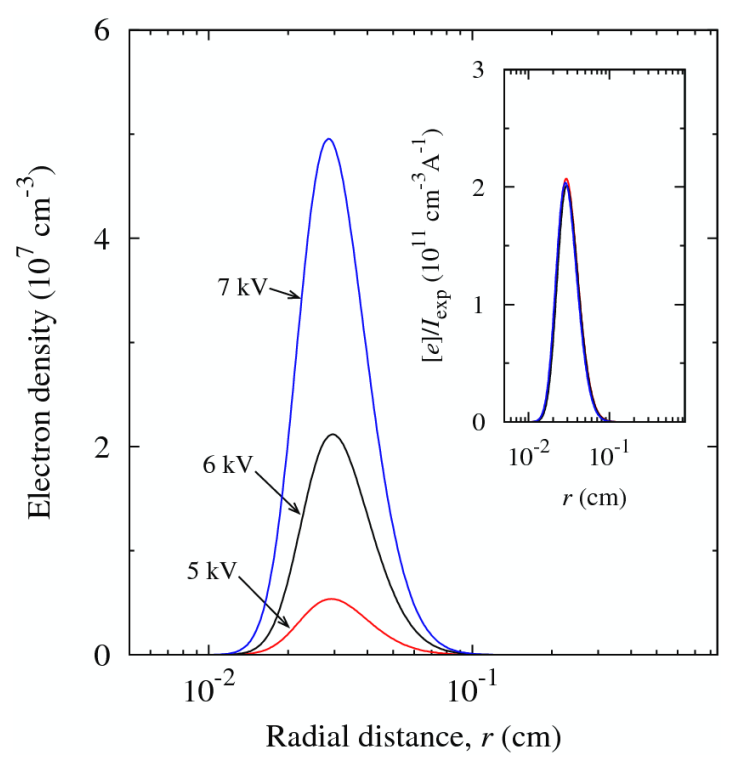

Figure 18. Radial distribution of electrons at the exit of the cylinder $(z=5 \mathrm{~cm})$ for $Q=200$ $\mathrm{cm}^{3} / \mathrm{min}$ and various applied voltages. The inset figure shows the electron density scaled with the current intensity.

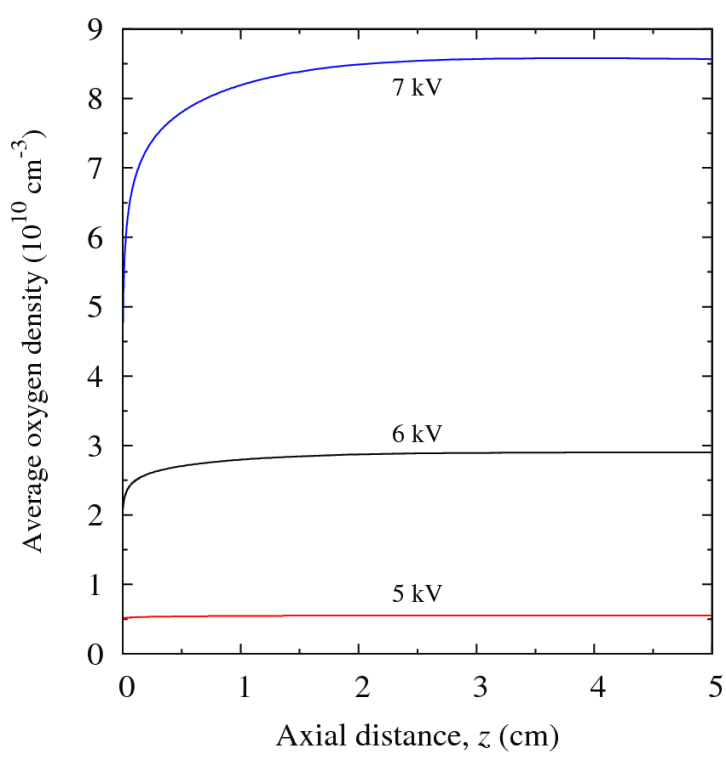

Figure 19. Radial average of atomic oxygen density as a function the axial distance for $R=0.85 \mathrm{~cm}, Q=$ $200 \mathrm{~cm}^{3} / \mathrm{min}$ and various applied voltages.

\subsection{The effect of applied voltage and time-averaged current.}

These two parameters are related through the current-voltage characteristic (figure 3) and affect the chemical kinetics in different forms. Firstly, the reaction rate constants of many reactions are increasing functions of the electric field, particularly, electron driven reactions. Secondly, the experimental value of current intensity has been used as a boundary condition in (10), which sets the number of secondary electrons released by the cathode. Thus, changing the applied voltage and current intensity will have immediate consequences on the number densities of charged and neutral species.

As shown in figure 18, the electron density increases very quickly when $V$ and $I_{\exp }$ are augmented. Indeed, the increase of electron density is linearly dependent on the current intensity, in agreement with [7]. This fact can be easily seen in the inset of figure 18, where the ratio of electron density to current intensity has been plotted against the radial distance. The results presented in figure 18 correspond to a gas flow rate of $200 \mathrm{~cm}^{3} / \mathrm{s}$ and to an axial distance of $z=5 \mathrm{~cm}$ (cylinder exit) but, as it was already indicated, they are essentially identical at any other value of $z$.

Figures 19 and 20 show the radial average of $\mathrm{O}$ and $\mathrm{O}_{3}$ as function of the axial distance to the gas inlet for different applied voltages. As for electrons, the density of these species also increases significantly when voltage and current are raised. Regarding atomic oxygen (figure 19), the augmentation of its density with $V$ and $I_{\exp }$ is linked to that of electrons, through reactions (R8) and (R9). Moreover, the reaction rate constants corresponding to these reactions are strongly activated by the electric field. For each voltage, the radial average of atomic oxygen density initially increases with the axial distance, and then becomes practically constant. As $V$ and $I_{\text {exp }}$ are raised, a longer distance is required to reach the steady density. The radial average of ozone density increases almost linearly with the axial distance (figure 20) and, at any value of $z$, the higher the applied voltage the higher the ozone density. At the highest applied voltage, a slight deviation from linearity can be observed.

Finally, the experimental measurements of ozone concentration, obtained by means of ultraviolet absorption spectrophotometry, are compared with the results of the numerical simulation (figure 21). Ozone concentration inside the discharge cell is evaluated as the 2D- 


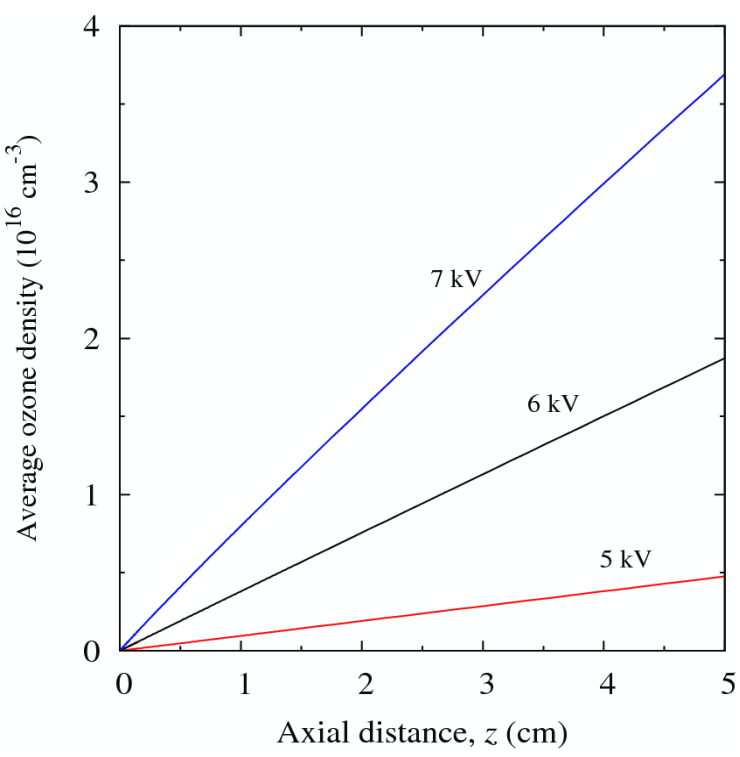

Figure 20. Radial average of ozone density as a function the axial distance for $R=0.85$, and $Q=$ $200 \mathrm{~cm}^{3} / \mathrm{min}$ and various applied voltages.

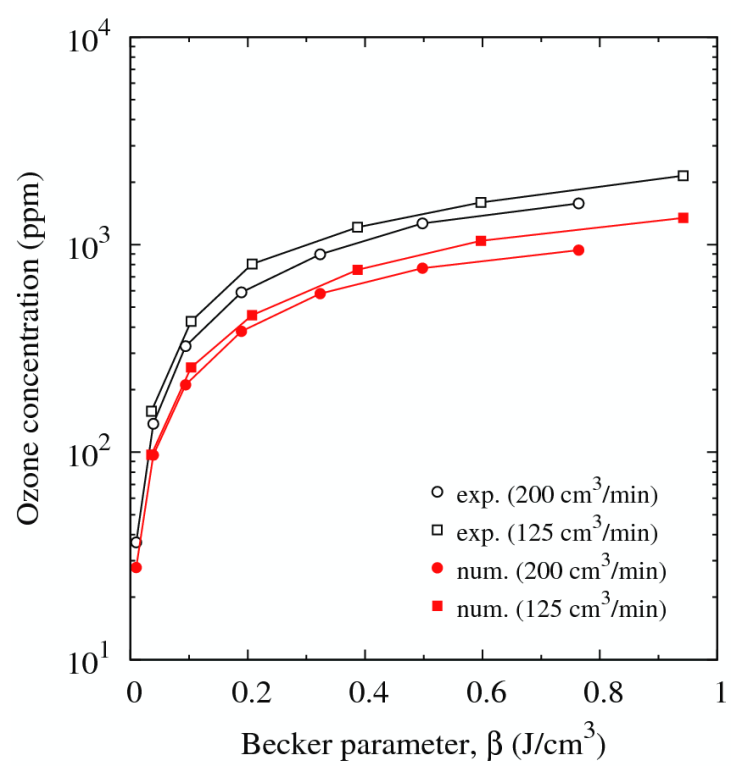

Figure 21. Spatially averaged ozone concentration inside the cylinder as a function of Becker parameter, $\beta=I_{\exp } V / Q$, for $R=0.85 \mathrm{~cm}$ and $Q=$ $200 \mathrm{~cm}^{3} / \mathrm{min}$ and $Q=125 \mathrm{~cm}^{3} / \mathrm{min}$.

spatial average of ozone density. The effect of the discharge parameters, $V$ and $I_{\text {exp }}$, is presented through Becker parameter, $\beta=I_{\exp } V / Q$. This parameter represents the electric energy density injected in the discharge cell. Every point in this figure corresponds to a different applied voltage and time-averaged current intensity. Simulation and experiments show an acceptable agreement, although numerical simulation tends to underestimate ozone concentration $(\sim 20$ $40 \%$ lower).

\subsection{The effect of gas flow rate and cylinder radius.}

Gas flow rate and cylinder radius also affect the generation of species and, particularly, ozone distribution. Increasing the gas flow rate reduces the residence time of the gas inside the cylinder and, therefore, the energy deposited by the electrical discharge in the gas. The effect of this parameter on the axial distribution of ozone can be seen in figure 22 , where the radial average of ozone density has been plotted as a function of the axial distance for three different values of the gas flow rate. In all the three cases, the applied voltage was $5 \mathrm{kV}$ and the timeaveraged current was very similar, in order to minimise the influence this parameter. Ozone density is observed to increase linearly with the axial distance and, as expected, the smaller the gas flow rate the higher the rate of ozone growth with distance.

Figure 23 illustrates the effect of modifying the cylinder radius on the axial variation of ozone, for a constant gas flow rate of $125 \mathrm{~cm}^{3} / \mathrm{min}$ and an applied a voltage of $5 \mathrm{kV}$. Increasing the cylinder radius has two opposite actions. On the one hand, the residence time of the gas inside the cylinder will be longer and, therefore, the electrical energy deposited in the gas will be higher, thus favoring ozone generation. On the other hand, the increase of the cylinder radius affects the electric field distribution and, consequently, the corona current. For example, for cylinder radii of $0.65 \mathrm{~mm}, 0.85 \mathrm{~mm}$ and $11 \mathrm{~mm}$, the averaged corona current at $5 \mathrm{kV}$ were $I=$ $109 \mu \mathrm{A}, 43 \mu \mathrm{A}$ and $26 \mu \mathrm{A}$, respectively. Since the number density of electrons depends crucially on the current density (actually, it is proportional to $I$ ), and these particles initiate the chemical activity leading to the generation of ozone, a reduction of cylinder radius should be accompanied by an increase in ozone density. According to the results shown in figure 23, this second effect dominates over the first one, since ozone density is found to be higher using smaller radii. Inside the cylinder, the distribution of ozone density increases linearly with the axial distance. 


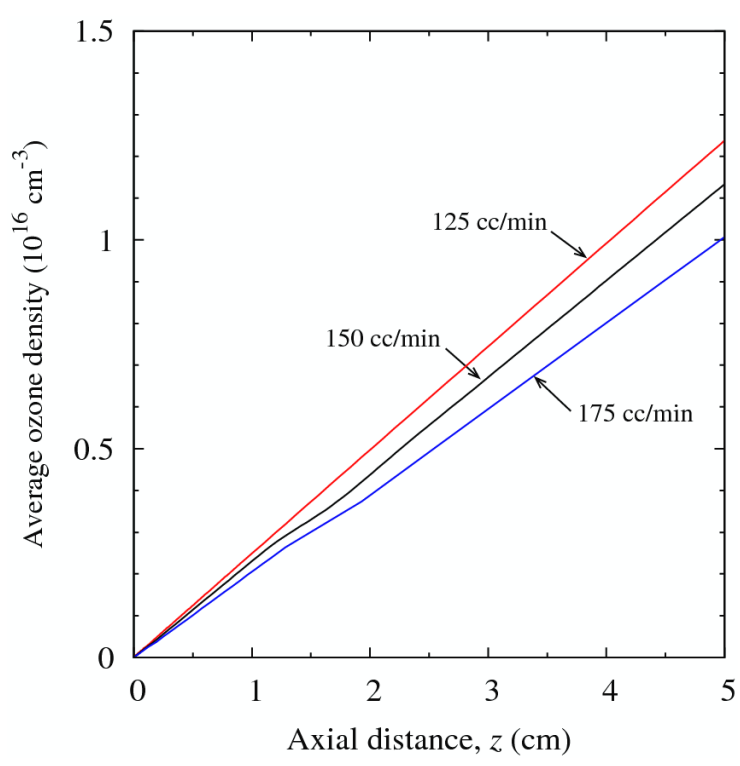

Figure 22. Radial average of ozone density as a function the axial distance for $V=5 \mathrm{kV}, R=0.85$ $\mathrm{cm}$ and various gas flow rates.

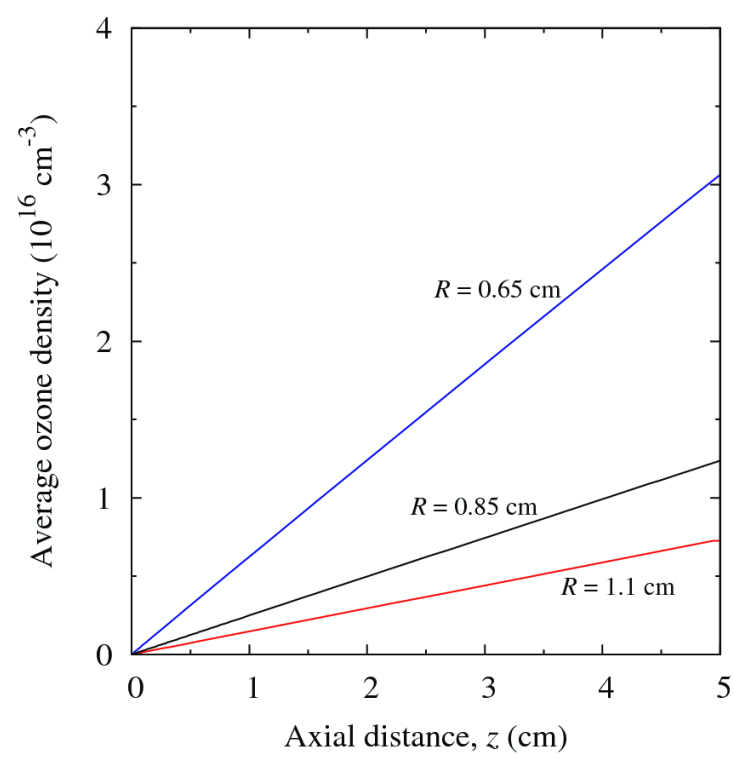

Figure 23. Radial average of ozone density as a function the axial distance for $V=5 \mathrm{kV}, Q=125$ $\mathrm{cm}^{3} / \mathrm{min}$ and different cylinder radii.

\section{Conclusions}

Negative wire-to-cylinder corona discharge with axial gas flow has been investigated using a fluid model that contains the fundamental physical and chemical processes occurring in the electrical discharge. In the model, the electric field is governed by Gauss equation, and it is coupled with the species densities and the reaction rates that are part of the continuity equations. The 2D spatial distributions of charged and neutral species have then been obtained by solving numerically the differential equations. It is worth mentioning the following results:

i) Regarding charged species, the spatial distribution of electrons, $\mathrm{O}^{+}, \mathrm{O}^{-}$and $\mathrm{O}_{2}^{+}$are practically independent of the axial distance. On the contrary, the number densities of $\mathrm{O}_{2}{ }^{+}, \mathrm{O}_{2}{ }^{-}$and $\mathrm{O}_{3}^{-}$depend strongly on ozone concentration, which varies along the cylinder. In the vicinity of the gas inlet, the densities of $\mathrm{O}_{2}{ }^{-}$and $\mathrm{O}_{3}{ }^{-}$are similar. At the exit of the cylinder, $\mathrm{O}_{3}{ }^{-}$is the only negative charge carrier in the drift region of the electrical discharge.

ii) As with respect to neutral species, their spatial distribution is very diverse, depending on their chemical kinetics. Hence, the densities of excited species $\mathrm{O}_{2}\left({ }^{1} \Delta_{\mathrm{g}}\right), \mathrm{O}_{2}\left({ }^{1} \Sigma_{\mathrm{g}}{ }^{+}\right)$y $\mathrm{O}_{2}{ }^{*}$ reach their maximum value soon after the gas inlet. Other species, however, are present all through the cylinder, like $\mathrm{O}\left({ }^{1} \mathrm{D}\right)$ and $\mathrm{O}$, or after a certain axial distance, like $\mathrm{O}_{3}{ }^{*}$.

iii) The spatial distribution of ozone varies considerably throughout the cylinder. It is generated in the active region of the corona discharge and, from there, it diffuses in the radial direction and it is advected in the axial direction. Therefore, its concentration increases in the direction of the flow.

The influence of applied voltage, gas flow and cylinder radius on the axial distribution of ozone has also been investigated numerically. According to the results, the radial average of ozone density always increases linearly in the direction of the flow, regardless of the values taken by these parameters. However, at any position along the cylinder, ozone density grows when the applied voltage is increased, the gas flow is decreased or the cylinder radius is reduced. An acceptable agreement between experiment and simulation was found for ozone concentration.

\section{References}


[1] Hadj-Ziane S, Held B, Pignolet P, Peyrous R, Benas J M and Coste C 1990 Ozone production in an oxygen-fed wire to cylinder ozonizer, J. Phys. D: Appl. Phys. 23 1390-5.

[2] Hadj-Ziane S, Held B, Pignolet P, Peyrous R and Coste C 1992 Ozone generation in an oxygen-fed wire-to-cylinder ozonizer at atmospheric pressure, J. Phys. D: Appl. Phys. $25677-$ 85.

[3] Loiseau J F, Lacassie F, Monge C, Peyrous R and Held B 1994 Numerical simulation of ozone axial andradial distribution in a cylindrical oxygen-fed ozonizer, J. Phys. D: Appl. Phys. 27 63-73.

[4] Chen J and Davidson J H 2002 Ozone production in the positive dc corona discharge: model and comparison to experiments Plasma Chem. Plasma Process. 22 495-522.

[5] Chen J and Davidson J H 2003 Ozone production in the negative dc corona: the dependence of discharge polarity Plasma Chem. Plasma Process. 23 501-18.

[6] Wang P and Chen J 2009 Numerical modelling of ozone production in a wire-cylinder corona discharge and comparison with a wire-plate corona J. Phys. D: Appl. Phys. 42035202 (8pp).

[7] Soria C, Pontiga F and Castellanos A 2004 Plasma chemical and electrical modelling of a negative dc corona in pure oxygen Plasma Sources Sci. Technol. 13 95-107.

[8] Yanallah K, Pontiga F, Fernández-Rueda A, Castellanos A and Belasri A 2008 Ozone generation by negative corona discharge: the effect of Joule heating J. Phys. D: Appl. Phys. 41 195206 (8pp).

[9] Yanallah K, Pontiga F, Fernández-Rueda A and Castellanos A 2009 Experimental investigation and numerical modelling of positive corona discharge: ozone generation $J$. Phys. D: Appl. Phys. 42 (2009) 065202 (8pp).

[10] Held B and Peyrous R 1998 Analytic calculations of ozone concentration in an oxygen-fed wire-to-cylinder ozonizer and comparison with the Vasil'ev relation. The European Physical Journal Applied Physics 473.

[11] Tkachenko N V 2006 Optical Spectroscopy: Methods and Instrumentations (Amsterdam: Elsevier B.V.)

[12] Vann Bush P and Snyder T R 1987 Laboratory analyses of corona discharges Journal of Electrostatics, 1983.

[13] Chang J S, Lawless P A and Yamamoto T 1991 Corona discharge processes IEEE Transactions on Plasma Science 191152.

[14] Davidson J H, and Shaughnessy E J 1986 Turbulence generation by electric body forces Experiments in Fluids 4, 17.

[15] Agraï N, and Castellanos A 1990 Linear convective patterns in cylindrical geometry for unipolar injection Physics of Fluids A 237.

[16] Chen J and Davidson J H 2003 Model of the Negative DC Corona Plasma: Comparison to the Positive DC Corona Plasma Plasma Chem. Plasma Process. 2383.

[17] Mikoviny T, Kocan M, Matejcik S, Mason N J and Skalny J D 2004 Experimental study of negative corona discharge in pure carbon dioxide and its mixtures with oxygen Journal of Physics D: Applied Physics 3764.

[18] Feng J Q 1999 An analysis of corona currents between two concentric cylindrical electrodes Journal of Electrostatics 4637.

[19] Belevtsev A A and Biberman L M 1983 On the Theory of Corona Discharge Beiträge aus der Plasmaphysik 23313. 
[20] Dutton J 1975 A survey of electron swarm data J. Phys. Chem. Ref. Data 4 577-856.

[21] Suzuki S, Itoh H, Ikuta N and Sekizawa H 1992 Reflection of diffusing metastable gas molecules at the boundary J. Phys. D: Appl. Phys. 25 1568-1573.

[22] Yanallah K, Hadj-Ziane S and Belasri A 2006 Ozone decomposition on walls Plasma Devices Oper. 14 215-222.

[23] Eliasson B, and Kogelschatz U 1986 Basic data for modeling electrical discharges in gases: oxygen Technical Report KLR 86-11 C, Brown Boveri. 